\title{
中国干旱半干旱区荒漠植物叶片(或同化枝)表皮微 形态特征
}

刘玉冰* 李新荣李蒙蒙刘丹 张雯莉

中国科学院西北生态环境资源研究院, 沙坡头沙漠试验研究站, 甘肃省寒区早区逆境生理与生态重点实验室, 兰州 730000

摘 要 为了探讨荒漠植物叶片表皮微形态结构对长期荒漠环境的适应特征及其分类学意义, 应用扫描电镜对中国干旱半 干旱荒漠区28科74属117种200多个自然居群的植物叶片(或同化枝)表皮微形态进行了研究。荒漠植物叶(或同化枝)表皮的基 本特征是: 表皮附属物相当丰富, 包括大量的表皮线毛、角质膜蜡质片层或晶体颗粒、表面瘤状或病状突起以及相对下陷且 密度较低的气孔器。对表皮微形态结构及附属物组成进行对比分析, 将荒漠植物粗分为 11 种基本类型, 包括表皮完全被形态 各异的蜡质层或表皮毛覆盖、不同形态类型的表皮毛和蜡质层结合、蜡质层与不同分布类型的气孔器或表皮毛结合, 以及各 种突起的表皮细胞与蜡质层的结合等。根据抗逆所依赖的表皮及其附属物微形态结构, 将荒漠植物适应环境胁迫的叶片表皮 微形态分为6种主要类型, 它们分别依赖于表皮毛、角质层蜡质、表皮凹凸结构、表面突起、混生的附属物以及上下表皮异 化特征。荒漠植物叶表皮微形态结构的适应特征是通过表皮附属物(线毛和角质膜蜡质层)与表皮结构(凹凸、乳突和气孔器) 的相互协调作用, 共同抵御强光、降低叶片的蒸腾来提高植物对干旱等不利环境的抗性。该研究在一定程度上阐明了荒漠植 物对逆境的适应机理及其演化趋势, 并为优良固沙植物的篮选提供了理论依据。

关键词＼cjkstart荒漠植物; 叶片; 同化枝; 表皮微形态; 干旱半干旱区

引用格式: 刘玉冰, 李新荣, 李蒙蒙, 刘丹, 张雯莉 (2016). 中国干旱半干旱区荒漠植物叶片(或同化枝)表皮微形态特征. 植物生态学报, 40, 1189-1207. doi: 10.17521/cjpe.2016.0129

\section{Leaf (or assimilation branch) epidermal micromorphology of desert plant in arid and semi- arid areas of China}

LIU Yu-Bing*, LI Xin-Rong, LI Meng-Meng, LIU Dan, and ZHANG Wen-Li

Shapotou Desert Research \& Experiment Station, and Key Laboratory of Stress Physiology and Ecology in Cold and Arid Regions of Gansu Province, Northwest Institute of Eco-environment and Resources, Chinese Academy of Sciences, Lanzhou 730000, China

\section{Abstract}

Aims Leaf epidermal micromorphology is an important adaptation of desert plants to arid environment. A micromorphological analysis of leaf epidermal tissue of desert plants was carried out in order to obtain qualitative and quantitative data on epidermal characteristics and to evaluate the long-term adaptive strategy of desert plants to aridity in desert conditions.

Methods The leaf (or assimilation branches) materials were sampled for more than 200 natural populations of 117 desert plant species from 74 genera and 28 families, in arid and semi-arid areas of China. The characteristics of leaf epidermal micromorphology of desert plants were then measured by scanning electron microscopy (SEM). Characteristics of epidermal cell, trichome, stomatal, cuticular wax on adaxial and abaxial surface are presented.

Important findings Leaf epidermal micromorphology of desert plants showed abundant diversity in different classification levels. The desert plants adapted to environmental stress can be divided into 11 basic morphological types according to the structure of the epidermis, and their characteristics of leaf epidermal morphology were classfied into 6 main types according to the relationships between stress resistance and structural characteristics of epidermal micromorphology and their appendages. The main epidermal appendages of desert plants (such as trichome, cuticular wax) and epidermal structures (concave-convex and papillary structure, stomata) could cooperate with each other to improve the resistance of desert plants to drought and other adverse environmental stress by resisting the strong light and reducing leaf transpiration.

收稿日期Received: 2016-04-07 接受日期Accepted: 2016-07-19

*E-mail: ybliu13@163.com 
Key words desert plants; leaf; assimilation branch; epidermal micromorphology; arid and semi-arid areas

Citation: Liu YB, Li XR, Li MM, Liu D, Zhang WL (2016). Leaf (or assimilation branch) epidermal micromorphology of desert plant in arid and semi-arid areas of China. Chinese Journal of Plant Ecology, 40, 1189-1207. doi: 10.17521/cjpe.2016.0129

植物作为生态系统的第一生产者, 受环境变化 的影响是直接而多方面的。叶片是植物进化过程中 对环境变化最敏感且可塑性较大的器官, 在不同的 选择压力下形成了各种适应类型(Hickey, 1984; 祁 如虎等, 1998; Gielwanowska et al., 2005), 其形态结 构特征最能体现环境因子的影响或植物对环境的适 应(王勋陵和王静, 1989; Krober et al., 2015)。

干旱半干旱区的荒漠环境属于一种极端环境, 降水稀少, 气候干燥, 昼夜温差大, 地面温度高, 土 壤贫㾑, 风沙活动强烈……这些恶劣条件无时不在 限制着荒漠植物的生存和繁衍。但即使在这种条件 下, 仍有许多植物分布于干旱半干旱区, 且能很好 地繁衍生息。那么, 这些植物有何特殊的形态结构 来适应环境呢? 如何通过植物形态结构特征判断其 适应能力? 这些问题引发不少科学家对荒漠植物研 究的极大关注。Schow提出“旱生植物”概念已有 100 多年了。国内外不少学者研究过旱生植物的形态结 构(Shield, 1950; 王勋陵和马䩀, 1999; 严巧娣等, 2008; Liu et al., 2012, 2015; Perrone et al., 2015), 但 以各自有限数量的旱生植物形态结构描述为主, 至 今未见对较大数量旱生植物叶片表皮微形态与结构 特征进行数量化整理, 并对其类型划分、变化规律、 演化趋势、适应对策等重要问题进行系统讨论的 报道。

植物叶片适应环境的形态结构变化是多方面 的。在众多生态因子中, 叶片受水分、温度和光因 子的影响最为显著(王勋陵和王静, 1989; 王勋陵, 1993; Aronne \& de Micco 2001; Arena et al., 2008; Jaleel et al., 2009a, 2009b), 主要表现为叶形的变 化、叶片表皮附属物的变化、叶片的厚度及解剖结 构的差异(Talukdar, 2015)。对于荒漠植物来说, 夏 季极端干旱时它们可能同时遭受以上各种环境因子 的胁迫。但其最主要的限制因子为水分, 因而表现 出典型的旱生植物形态结构特征。由于遗传因子与 环境因子的共同作用, 在旱生植物结构的适应性上 出现了两种演化趋势, 即趋同性和趋异性, 也就是 说, 在相同环境下的植物演化出相似的形态结构适 应性, 而不同环境下的同类植物演化出不同的形态
结构(Lakusic et al., 2010)。因此, 要系统分析荒漠植 物叶片形态结构特征的适应性变化, 需要将一个区 域不同植物和不同梯度生境下的同一植物做全面分 析。

植物叶片对环境的响应首先是叶片表皮对环境 的感应和变化(Pal et al., 2002; Bargel et al., 2004; Koch et al., 2009; Adebowale et al., 2014)。生长于干 燥的气候和土壤条件下的荒漠植物, 叶表皮细胞会 变小, 切向壁加厚, 具有内皮层。叶表皮角质膜厚度 增加, 角质层由光滑变得粗糙, 能够反射阳光, 减 少叶片表面空气的流动, 降低蒸腾作用, 防止水分 过度丧失(贺金生等, 1994; 杨明博等, 2007)。气孔的 分布特征、密度和面积等都会受到影响, 气孔多分 布于叶片下表皮, 这种分布模式既可促进植物与外 界环境进行气体交换, 又能保持水分。随着环境中 水分和湿度的减少, 气孔密度增加, 气孔面积则向 小型化发展, 气孔多下陷形成气孔窝或其上有突出 的角质膜(Sam et al., 2000; Bosabalidis \& Kofidis, 2002; 高建平等, 2003; Xu \& Zhou, 2008; Gan et al., 2010; de Micco \& Aronne, 2012)。叶表皮附属物(如 表皮毛和表面病状突起物)也发生变化, 它们可有 效地避免叶肉组织受损(Gairola et al., 2009; Koch et al., 2009; Gomes et al., 2011; Noman et al., 2012), 表 皮蜡质(waxes) 晶体形成二维或三维结构, 具有降低 表皮的可湿性以及反射强光等作用(Wagner et al., 2003; Koch \& Ensikat, 2008)。

植物叶表皮微形态特征已用于解决物种分类问 题、建立物种进化关系、阐明表皮微形态结构的生 态适应性等多种研究目的(Dickison, 2000; Scatena et al., 2005; Stenglein et al., 2005; Aliero et al., 2006; Chen et al., 2010; Zhou \& Xia, 2012; Adebowale et al., 2014; Deng et al., 2014; Zhang et al., 2014; Francisco et al., 2015; 朱广龙等, 2016)。为了探讨荒漠植 物叶片表皮微形态结构的适应特征及其亲缘关系, 选择分布于同一区域的不同植物和不同降水量梯度 生境下的同一植物, 利用扫描电镜观察分析了 117 种荒漠植物叶片的表皮微形态结构, 旨在阐明荒漠 植物对逆境的适应机理及其演化趋势, 并为优良固 
沙植物的篎选提供理论依据。

\section{1 材料和方法}

\section{1 野外采样样品}

荒漠植物叶片采自中国干旱半干旱荒漠区野外 自然生境(包括人工固沙植被和自然演替植被), 包 含28科74属117种200多个自然居群的植物叶片(或 同化枝)，采集的物种及采集地地理位置见附录 $\mathrm{I}$ 。 2012年和2013年的5-7月, 采集成熟的嫩叶和同化 枝。长度小于 $1.0 \mathrm{~cm}$ 的叶片直接放入固定液, 大于 $1.0 \mathrm{~cm}$ 的叶片或同化枝取中段部分剪成 $0.5 \mathrm{~cm} \times 0.5$ $\mathrm{cm}$ 大小或 $0.5 \mathrm{~cm}$ 长度放入固定液, 同化枝选取 0.5 $\mathrm{cm}$ 中部片段放入固定液。固定液为 $2.5 \%$ 戈二醛磷酸 缓冲液 $\left(0.1 \mathrm{~mol} \cdot \mathrm{L}^{-1}, \mathrm{pH} 7.2\right)$ 。

\section{2 扫描电镜观察}

扫描电镜材料的制备参考Liu等(2012)的方法, 制备过程如下: 将固定 $24 \mathrm{~h}$ 后的材料经磷酸缓冲液 (0.1 mol $\left.\cdot \mathrm{L}^{-1}, \mathrm{pH} 7.2\right)$ 清洗2次, 各10 min, 然后用 $1.0 \%$ $\mathrm{OsO}_{4}$ 磷酸缓冲液进行最后固定过夜。过夜后的材料 用以上磷酸缓冲液清洗后, 在不同浓度的乙醇 $(30 \%$ 、 $50 \% 、 70 \% 、 96 \% 、 100 \%)$ 中进行脱水, 乙醇浓度逐渐 增加。然后在干燥器JFD-310中干燥后, 喷20 nm厚的 胶体金, 用扫描电镜(JSM-6380, JEOL, Tokyo, Japan) 观察叶上、下表皮微形态特征并进行拍照。

\section{2 结果}

\section{1 荒漠植物叶片(或同化枝)表皮微形态基本特征}

荒漠植物由于生境严酷, 叶片一般较小, 特别 是灌木, 有些叶片缩小为细棒状或完全退化, 以同 化枝来代替叶片进行光合过程而完成植物的生活 史, 如麻黄属(Ephedra)、沙拐患属(Calligonum)、梭 梭属(Haloxylon)植物。因此, 对于有叶片的植物选 取叶片部分, 而叶片退化的材料选取同化枝进行主 要光合器官的表皮微形态结构特征分析。

通过对中国干旱半干旱荒漠区28科74属117种 200多个自然居群的植物叶片表皮微形态特征的扫 描, 发现荒漠植物叶片(或同化枝)表皮细微结构存 在显著差异(表1)。表皮细胞形态总体有两种: 不规 则形和多边形, 但不同植物细胞形态各异, 棒状叶 片和同化枝表皮细胞多为长条形, 片状叶片细胞形 态一般为不规则或多边形。表皮细胞垂周壁式样有 直线形、弓形或曲线形。荒漠植物叶片表皮的一个
明显特征是表皮附属物相当丰富，包括大量的表皮 线毛、角质膜蜡质片层或晶体颗粒、表面瘤状或衤 状突起, 以及相对下陷且密度较低的气孔器。表皮 线毛类型多样, 从结构上可划分为具囊状(腺毛)和 不具囊状(非腺毛)两类, 从形态上可划分为有囊状、 柳叶状、针状、卷丝状、星状、小草状、棒状等, 且 具有表皮线毛的植物一般线毛数量较多。表面蜡质 晶体形态各异, 有颗粒状、直立鳞片状、膜片状、 壳状或痂状、晶簇状、棒状以及多种形态的混合, 且 大多数植物角质膜蜡质层晶体密度很高。灌木的气 孔相对于草本来说, 多数为下陷型, 气孔密度为 100-200个 $\cdot \mathrm{mm}^{-2}$ 的植物较多, 有少数植物的气孔集 中于叶面的其中一面，而另一面没有气孔。

\section{2 荒漠植物叶片(或同化枝)表皮微形态结构基本 类型}

按照表皮微形态结构和表皮附属物的组成, 荒 漠植物表皮微形态可分为以下 11 个主要类型:

(1)表面粗糙 上下表皮细胞完全被表皮角质膜 蜡质层覆盖, 蜡质层在表皮上如同一个罩壳阻断表 皮与外界的直接接触, 表皮细胞形态需要去除蜡质 层才可见, 蜡质形态有颗粒状、膜片状、晶簇状或多 种形态的混合, 表面不平滑。代表植物有膜果麻黄 (Ephedra przewalskii)(图 1A)、霸王 (Zygophyllum xanthoxylon)(图1B)灌木铁线莲(Clematis fruticosa)等。

(2)表面完全被毛 形态各异的表皮线毛完全 覆盖叶片上下表面(图2), 表皮细胞形态需要去除掉 线毛才可观察到, 线毛的形态有柳叶状、针状、卷 丝状、星状、小草状等。代表植物有沙柊(Elaeagnus angustifolia)(图2A)、刺疮㽽(Olgaea tangutica)(图 2B)、柠条锦鸡儿(Caragana korshinskii)、卷叶锦鸡 儿 (Caragana ordosica)、沙冬青 (Ammopiptanthus mongolicus)、唐古特白刺(Nitraria tangutorum)(图 2C)、珍珠猪毛菜(Salsola passerina)(图2D)、驼线藜 (Ceratoides latens)(图2E)、著状亚菊(Ajania achilloides)(图2F)等。

(3)表皮被囊状毛 上下表皮细胞形态清晰可 见, 表皮线毛附属物为囊状, 表皮有或无蜡质层覆 盖(图3)。代表植物有甘草(Glycyrrhiza uralensis)(图 3A)、百里香(Thymus mongolicus)(图3B)、单脉大黄 (Rheum uninerve)(图3C)等。

(4)表皮囊状毛和其他形态线毛混生 表皮细 胞被完全覆盖或不完全覆盖, 囊状和非囊状线毛共 
1192 植物生态学报 Chinese Journal of Plant Ecology 2016, 40 (11): 1189-1207

表1 荒漠植物表皮微形态基本特征代码表

Table 1 Characteristics of the epidermal micromorphology of desert plants

\begin{tabular}{|c|c|c|c|c|c|c|c|c|c|c|c|c|c|c|c|}
\hline 种名 Species name & $\begin{array}{c}\text { Cell } \\
\text { shape }\end{array}$ & $\begin{array}{l}\mathrm{CW} \\
\mathrm{ada}\end{array}$ & $\begin{array}{l}\mathrm{CW} \\
\mathrm{aba}\end{array}$ & $\begin{array}{l}\text { Papillae } \\
\text { ada }\end{array}$ & $\begin{array}{l}\text { Papillae } \\
\text { aba }\end{array}$ & $\begin{array}{l}\text { Trichome } \\
\text { type }\end{array}$ & $\begin{array}{l}\text { Trichome } \\
\text { ada }\end{array}$ & $\begin{array}{l}\text { Trichome } \\
\text { aba }\end{array}$ & $\begin{array}{c}\text { Wax } \\
\text { ada }\end{array}$ & $\begin{array}{c}\text { Wax } \\
\text { aba }\end{array}$ & $\begin{array}{c}\text { St } \\
\text { type }\end{array}$ & $\begin{array}{l}\text { St-s } \\
\text { ada }\end{array}$ & $\begin{array}{l}\text { St-s } \\
\text { aba }\end{array}$ & $\begin{array}{c}\text { St } \\
\text { ada }\end{array}$ & $\begin{array}{c}\mathrm{St} \\
\mathrm{aba}\end{array}$ \\
\hline 沙地柏 Sabina vulgaris & 0 & 0 & 0 & 0 & 0 & - & 0 & 0 & 1 & 1 & 0 & 1 & - & 1 & 0 \\
\hline 膜果麻黄 Ephedra przewalskii & 0 & 0 & 0 & 1 & 1 & - & 0 & 0 & 1 & 1 & 0 & 1 & 1 & 1 & 1 \\
\hline 斑子麻黄 Ephedra rhytidosperma & 0 & 0 & 0 & 1 & 1 & - & 0 & 0 & 1 & 1 & 0 & 1 & 1 & 2 & 2 \\
\hline 草麻黄 Ephedra sinica & 0 & 0 & 0 & 1 & 1 & - & 0 & 0 & 1 & 1 & 0 & 1 & 1 & 2 & 2 \\
\hline 芦苇 Phragmites communis & 0 & 0 & 0 & 1 & 1 & - & 0 & 0 & 1 & 1 & 3 & 1 & 1 & 2 & 2 \\
\hline 小獐毛 Aeluropus littoralis & 0 & 0 & 0 & 1 & 1 & 0 & 1 & 0 & 1 & 1 & 3 & 1 & 1 & 1 & 1 \\
\hline 戈壁天冬 Asparagus gobicu & 0 & 0 & 0 & 0 & 0 & - & 0 & 0 & 1 & 1 & 3 & 1 & 1 & 1 & 1 \\
\hline 沙葱 Allium mongolicum & 0 & 0 & 0 & 0 & 0 & - & 0 & 0 & 0 & 0 & 3 & 1 & 1 & 2 & 2 \\
\hline 沙非 Allium bidentaum & 0 & 0 & 0 & 0 & 0 & - & 0 & 0 & 0 & 0 & 3 & 1 & 1 & 2 & 2 \\
\hline 沙独尾草 Eremurus inderiensis & 0 & 0 & 0 & 0 & 0 & - & 0 & 0 & 0 & 0 & 3 & 1 & 1 & 1 & 1 \\
\hline 胡杨 Populus euphratica & 1 & 1 & 1 & 0 & 0 & 0 & 1 & 1 & 1 & 1 & 2 & 1 & 1 & 2 & 2 \\
\hline 黄柳 Salix gordejevii & 1 & 1 & 1 & 0 & 0 & 0 & 1 & 0 & 1 & 1 & 2 & 0 & 0 & 2 & 1 \\
\hline 旱柳 Salix capitata & 1 & 1 & 1 & 0 & 0 & 0 & 2 & 1 & 1 & 1 & 2 & 0 & 0 & 1 & 1 \\
\hline 乌柳 Salix microstachya & 1 & 1 & 1 & 0 & 0 & 0 & 3 & 2 & 0 & 1 & 0 & 0 & 0 & 2 & 1 \\
\hline 沙柳 Salix psammophila & 1 & 1 & 1 & 0 & 0 & 0 & 1 & 0 & 1 & 1 & 2 & 0 & 0 & 2 & 1 \\
\hline 沙木蓼 Atraphaxis bracteata & 0 & 1 & 1 & 0 & 0 & - & 0 & 0 & 0 & 0 & 1 & 0 & 0 & 2 & 2 \\
\hline 木蓼 Atraphaxis frutescens & 0 & 1 & 1 & 0 & 0 & - & 0 & 0 & 1 & 1 & 1 & 0 & 0 & 2 & 2 \\
\hline 西伯利亚苶 Polygonum sibiricum & 0 & 1 & 1 & 0 & 0 & 0 & 1 & 1 & 1 & 1 & 1 & 0 & 0 & 2 & 2 \\
\hline 白皮沙拐杳 Calligonum leucocladum & 0 & 0 & 0 & 0 & 0 & - & 0 & 0 & 1 & 1 & 0 & 0 & 0 & 1 & 1 \\
\hline 沙拐束 Calligonum mongolicum & 0 & 0 & 0 & 0 & 0 & - & 0 & 0 & 1 & 0 & 0 & 0 & 0 & 2 & 2 \\
\hline 单脉大黄 Rheum uninerve & 1 & 1 & 1 & 0 & 0 & 1 & 1 & 1 & 1 & 1 & 1 & 0 & 0 & 2 & 2 \\
\hline 短叶假木贼 Anabasis brevifolia & 1 & 1 & 1 & 0 & 0 & - & 0 & 0 & 1 & 1 & 0 & 0 & 0 & 1 & 1 \\
\hline 梭梭 Haloxylon ammodendron & 1 & 1 & 1 & 0 & 0 & - & 0 & 0 & 0 & 0 & 0 & 1 & 1 & 2 & 2 \\
\hline 驼线藜 Ceratoides latens & 0 & 1 & 1 & 0 & 0 & 1 & 3 & 3 & 0 & 0 & 0 & 0 & 0 & 2 & 2 \\
\hline 珍珠猪毛菜 Salsola passerina & 0 & 1 & 1 & 0 & 0 & 0 & 3 & 3 & 0 & 0 & 0 & 0 & 0 & 2 & 2 \\
\hline 木本猪毛菜 Salsola arbuscula & 1 & 1 & 1 & 0 & 0 & - & 0 & 0 & 1 & 1 & 0 & 1 & 1 & 2 & 2 \\
\hline 松叶猪毛菜 Salsola laricifolia & 1 & 1 & 1 & 0 & 0 & - & 0 & 0 & 1 & 1 & 0 & 0 & 0 & 1 & 1 \\
\hline 猪毛菜 Salsola collina & 1 & 1 & 1 & 0 & 0 & - & 0 & 0 & 0 & 0 & 0 & 1 & 1 & 2 & 2 \\
\hline 合头草 Sympegma regelii & 0 & 0 & 0 & 0 & 1 & - & 0 & 0 & 1 & 1 & 0 & 0 & 0 & 1 & 1 \\
\hline 盐爪爪 Kalidium foliatum & 0 & 1 & 0 & 0 & 0 & 0 & 2 & 1 & 1 & 1 & 0 & 1 & 1 & 1 & 1 \\
\hline 细枝盐爪爪 Kalidium gracile & 1 & 1 & 1 & 0 & 0 & 0 & 2 & 1 & 1 & 1 & 0 & 1 & 1 & 1 & 1 \\
\hline 雾冰藜 Bassia dasyphylla & 0 & 1 & 1 & 0 & 0 & 1 & 2 & 2 & 1 & 1 & 0 & 0 & 0 & 1 & 1 \\
\hline 沙米 Agriophyllum squarrosum & 0 & 0 & 0 & 0 & 0 & 0 & 2 & 2 & 0 & 0 & 0 & 0 & 0 & 2 & 2 \\
\hline 角果藜 Ceratocarpus arenarius & 0 & 0 & 0 & 0 & 0 & 0 & 2 & 2 & 0 & 0 & 0 & 0 & 0 & 2 & 2 \\
\hline 叉毛蓬 Petrosimonia sibirica & 1 & 1 & 1 & 1 & 1 & 0 & 1 & 1 & 1 & 1 & 0 & 0 & 0 & 2 & 2 \\
\hline 灌木铁线莲 Clematis fruticosa & 1 & 0 & 0 & 0 & 0 & 0 & 1 & 1 & 1 & 1 & 0 & 1 & 1 & 1 & 1 \\
\hline 角茴香 Hypecoum erectum & 0 & 0 & 0 & 0 & 0 & - & 0 & 0 & 0 & 0 & 0 & 1 & 1 & 1 & 1 \\
\hline 沙芥 Pugionium cornutum & 1 & 1 & 1 & 0 & 0 & - & 0 & 0 & 1 & 1 & 0 & 0 & 0 & 2 & 2 \\
\hline 串珠芥 Torularia humilis & 1 & 1 & 1 & 0 & 0 & 0 & 2 & 2 & 1 & 1 & 0 & 0 & 0 & 2 & 2 \\
\hline 卷果澀芥 Malcolmia scorpioides & 1 & 1 & 1 & 0 & 0 & - & 0 & 0 & 1 & 1 & 0 & 0 & 0 & 1 & 1 \\
\hline 瓦松 Orostachys fimbriatus & 1 & 1 & 1 & 0 & 0 & - & 0 & 0 & 0 & 0 & 1 & 0 & 0 & 2 & 2 \\
\hline 绵刺 Potaninia mongolica & 1 & 1 & 1 & 0 & 0 & 0 & 2 & 1 & 0 & 0 & 0 & 0 & 0 & 1 & 1 \\
\hline 蒙古扁桃 Prunus mongolica & 1 & 1 & 1 & 0 & 0 & - & 0 & 0 & 1 & 1 & 2 & - & 0 & 0 & 3 \\
\hline 柄扁桃 Prunus pedunculata & 1 & 1 & 1 & 0 & 0 & 0 & 1 & 1 & 1 & 1 & 0 & - & 0 & 0 & 2 \\
\hline $\begin{array}{c}\text { 准噶尔无叶豆 Eremosparton } \\
\text { songoricum }\end{array}$ & 1 & 0 & 0 & 0 & 0 & 0 & 2 & 2 & 0 & 0 & 0 & 1 & 1 & 2 & 2 \\
\hline 苦豆子 Sophora alopecuroides & 1 & 1 & 1 & 0 & 0 & 0 & 3 & 3 & 0 & 0 & 0 & 1 & 1 & 2 & 2 \\
\hline 沙冬青 Ammopiptanthus mongolicus & 1 & 1 & 1 & 0 & 0 & 0 & 3 & 3 & 0 & 0 & 0 & 1 & 1 & 2 & 2 \\
\hline 披针叶黄华 Thermopsis schischkinii & 1 & 1 & 1 & 0 & 0 & 0 & 3 & 3 & 1 & 0 & 0 & 1 & 1 & 2 & 2 \\
\hline 骆驼刺 Alhagi sparsifolia & 1 & 1 & 1 & 0 & 0 & 0 & 2 & 2 & 1 & 1 & 0 & 0 & 0 & 2 & 2 \\
\hline 兴安胡枝子 Lespedeza davurica & 1 & 1 & 1 & 0 & 0 & 0 & 1 & 3 & 1 & 1 & 0 & 0 & 0 & 3 & 3 \\
\hline
\end{tabular}

www.plant-ecology.com 
表1 (续) Table 1 (continued)

\begin{tabular}{|c|c|c|c|c|c|c|c|c|c|c|c|c|c|c|c|}
\hline 种名 Species name & $\begin{array}{c}\text { Cell } \\
\text { shape }\end{array}$ & $\begin{array}{l}\text { CW } \\
\text { ada }\end{array}$ & $\begin{array}{l}\text { CW } \\
\text { aba }\end{array}$ & $\begin{array}{c}\text { Papillae } \\
\text { ada }\end{array}$ & $\begin{array}{c}\text { Papillae } \\
\text { aba }\end{array}$ & $\begin{array}{c}\text { Trichome } \\
\text { type }\end{array}$ & $\begin{array}{c}\text { Trichome } \\
\text { ada }\end{array}$ & $\begin{array}{c}\text { Trichome } \\
\text { aba }\end{array}$ & $\begin{array}{l}\text { Wax } \\
\text { ada }\end{array}$ & $\begin{array}{l}\text { Wax } \\
\text { aba }\end{array}$ & $\begin{array}{c}\text { St } \\
\text { type }\end{array}$ & $\begin{array}{l}\text { St-s } \\
\text { ada }\end{array}$ & $\begin{array}{l}\text { St-s } \\
\text { aba }\end{array}$ & $\begin{array}{c}\text { St } \\
\text { ada }\end{array}$ & $\begin{array}{c}\mathrm{St} \\
\mathrm{aba}\end{array}$ \\
\hline 小叶锦鸡儿 Caragana microphylla & 0 & 1 & 1 & 0 & 0 & 0 & 3 & 3 & 1 & 1 & 0 & 0 & 0 & 2 & 2 \\
\hline 中间锦鸡儿 Caragana intermedia & 0 & 1 & 1 & 0 & 0 & 0 & 3 & 3 & 1 & 1 & 0 & 0 & 0 & 2 & 2 \\
\hline 柠条锦鸡儿 Caragana korshinskii & 0 & 1 & 1 & 0 & 0 & 0 & 3 & 3 & 1 & 1 & 0 & 0 & 0 & 2 & 2 \\
\hline 荒漠锦鸡儿 Caragana roborovskyi & 0 & 1 & 1 & 0 & 0 & 0 & 2 & 3 & 1 & 1 & 0 & 1 & 1 & 1 & 1 \\
\hline 卷叶锦鸡儿 Caragana ordosica & 0 & 1 & 1 & 0 & 0 & 0 & 3 & 3 & 1 & 1 & 0 & 1 & 1 & 1 & 1 \\
\hline 刺叶锦鸡儿 Caragana acanthophylla & 0 & 1 & 1 & 0 & 0 & 0 & 2 & 2 & 1 & 1 & 0 & 1 & 1 & 2 & 1 \\
\hline 短脚锦鸡儿 Caragana brachypoda & 0 & 1 & 1 & 0 & 0 & 0 & 1 & 1 & 1 & 1 & 0 & 1 & 0 & 2 & 1 \\
\hline 狭叶锦鸡儿 Caragana stenophylla & 0 & 1 & 1 & 0 & 0 & 0 & 1 & 1 & 1 & 1 & 0 & 1 & 0 & 2 & 1 \\
\hline 红花锦鸡儿 Caragana rosea & 0 & 1 & 1 & 0 & 0 & - & 0 & 0 & 1 & 1 & 0 & 0 & 0 & 1 & 2 \\
\hline 甘草 Glycyrrhiza uralensis & 1 & 1 & 1 & 0 & 0 & 1 & 1 & 2 & 1 & 1 & 0 & 0 & 0 & 3 & 3 \\
\hline 细枝岩黄耆 Hedysarum scoparium & 0 & 1 & 0 & 0 & 0 & 0 & 2 & 2 & 1 & 1 & 0 & 1 & 0 & 2 & 1 \\
\hline 塔落岩黄芪 Hedysarum fruticosum & 0 & 1 & 1 & 0 & 0 & 0 & 1 & 2 & 1 & 1 & 0 & 0 & 0 & 2 & 1 \\
\hline 沙珍棘豆 Oxytropis psammocharis & 0 & 1 & 1 & 0 & 0 & 0 & 3 & 3 & 1 & 0 & 0 & 0 & 0 & 2 & 2 \\
\hline 山雀棘豆 Oxytropis avis & 0 & 1 & 1 & 0 & 0 & 0 & 2 & 2 & 1 & 0 & 0 & 0 & 0 & 2 & 2 \\
\hline 猫头刺 Oxytropis aciphylla & 0 & 0 & 0 & 0 & 0 & 0 & 2 & 2 & 1 & 0 & 0 & 1 & 0 & 2 & 1 \\
\hline 草珠黄芪 Astragalus capillipes & 0 & 1 & 1 & 0 & 0 & 0 & 1 & 1 & 1 & 1 & 1 & 1 & 1 & 2 & 2 \\
\hline 狭叶米口袋 Gueldenstaedtia stenophylla & 0 & 1 & 1 & 0 & 0 & 0 & 1 & 2 & 1 & 1 & 1 & 1 & 1 & 3 & 3 \\
\hline 陇牛儿苗 Erodium stephanianum & 1 & 1 & 1 & 0 & 0 & 0 & 1 & 1 & 0 & 0 & 0 & 0 & 0 & 3 & 3 \\
\hline 泡泡刺 Nitraria sphaerocarpa & 0 & 1 & 1 & 0 & 0 & - & 0 & 0 & 0 & 0 & 0 & 1 & 1 & 3 & 3 \\
\hline 唐古特白刺 Nitraria tangutorum & 0 & 1 & 1 & 0 & 0 & 0 & 3 & 3 & 1 & 0 & 0 & 1 & 1 & 2 & 2 \\
\hline 小果白刺 Nitraria sibirica & 0 & 1 & 1 & 0 & 0 & 0 & 3 & 3 & 1 & 0 & 0 & 1 & 1 & 2 & 2 \\
\hline 大白刺 Nitraria roborowskii & 0 & 1 & 1 & 0 & 0 & 0 & 3 & 3 & 1 & 0 & 0 & 1 & 1 & 2 & 2 \\
\hline 多裂骆驼蓬 Peganum multisectum & 1 & 0 & 0 & 0 & 0 & - & 0 & 0 & 0 & 0 & 0 & 0 & 0 & 2 & 2 \\
\hline 骆驼蓬 Peganum harmala & 1 & 0 & 0 & 0 & 0 & - & 0 & 0 & 0 & 0 & 0 & 0 & 0 & 2 & 2 \\
\hline 甘肃霸王 Zygophyllum kansuense & 1 & 1 & 1 & 0 & 0 & - & 0 & 0 & 1 & 1 & 0 & 1 & 1 & 2 & 2 \\
\hline 霸王 Zygophyllum xanthoxylon & 1 & 1 & 1 & 0 & 0 & - & 0 & 0 & 1 & 1 & 0 & 0 & 0 & 2 & 2 \\
\hline 蝎虎霸王 Zygophyllum mucronatum & 1 & 1 & 1 & 0 & 0 & 0 & 1 & 0 & 1 & 1 & 0 & 0 & 0 & 2 & 2 \\
\hline 箬藜 Tribulus terrestris & 0 & 1 & 1 & 0 & 0 & 0 & 2 & 3 & 0 & 0 & 0 & 0 & 0 & 3 & 3 \\
\hline 北拟云香 Haplophyllum dauricum & 0 & 0 & 0 & 0 & 0 & - & 0 & 0 & 1 & 1 & 0 & 1 & 1 & 3 & 2 \\
\hline 短生大戟 Euphorbia turczaninovii & 0 & 0 & 0 & 0 & 0 & - & 0 & 0 & 1 & 1 & 0 & 0 & 0 & 3 & 3 \\
\hline 乳浆大戟 Euphorbia esula & 0 & 0 & 0 & 0 & 0 & - & 0 & 0 & 1 & 1 & 0 & 1 & 0 & 2 & 3 \\
\hline 红砂 Reaumuria soongorica & 1 & 1 & 1 & 0 & 0 & - & 0 & 0 & 1 & 1 & 0 & 1 & 1 & 1 & 1 \\
\hline 五柱红砂 Reaumuria kaschgarica & 1 & 1 & 1 & 0 & 0 & - & 0 & 0 & 1 & 1 & 0 & 1 & 1 & 1 & 1 \\
\hline 长叶红砂 Reaumuria trigyna & 1 & 1 & 1 & 0 & 0 & - & 0 & 0 & 1 & 1 & 0 & 1 & 1 & 1 & 1 \\
\hline 柽柳 Tamarix chinensis & 1 & 1 & 1 & 0 & 0 & - & 0 & 0 & 1 & 1 & 0 & 1 & 1 & 1 & 1 \\
\hline 多枝柽柳 Tamarix ramosissima & 1 & 1 & 1 & 0 & 0 & - & 0 & 0 & 1 & 1 & 0 & 1 & 1 & 1 & 1 \\
\hline 半日花 Helianthemum songaricum & 0 & 1 & 1 & 0 & 0 & 0 & 2 & 3 & 1 & 0 & 0 & 1 & 0 & 2 & 1 \\
\hline 沙本 Elaeagnus angustifolia & 0 & 1 & 1 & 0 & 0 & 0 & 3 & 3 & 0 & 0 & 0 & - & 0 & 0 & 1 \\
\hline 沙棘 Hippophae rhamnoides & 0 & 1 & 1 & 0 & 0 & 0 & 2 & 3 & 1 & 0 & 0 & - & 0 & 0 & 1 \\
\hline 黄花补血草 Limonium aureum & 1 & 0 & 0 & 1 & 1 & - & 0 & 0 & 1 & 1 & 0 & 0 & 0 & 2 & 2 \\
\hline 罗布麻 Apocynum venetum & 1 & 1 & 1 & 1 & 1 & 1 & 1 & 1 & 1 & 1 & 0 & 1 & 1 & 1 & 1 \\
\hline 杜柳 Periplocasepium & 1 & 1 & 1 & 0 & 0 & - & 0 & 0 & 0 & 0 & 0 & - & 0 & 0 & 3 \\
\hline 鹅线藤 Cynanchum chinense & 0 & 1 & 1 & 0 & 0 & 0 & 1 & 1 & 0 & 0 & 0 & 1 & 1 & 2 & 3 \\
\hline 地梢瓜 Cynanchum thesioides & 1 & 1 & 1 & 0 & 0 & 1 & 2 & 2 & 1 & 1 & 0 & 0 & 0 & 2 & 3 \\
\hline 牛心朴子 Cynanchum komarovii & 0 & 1 & 1 & 0 & 0 & - & 0 & 0 & 1 & 1 & 0 & 1 & 1 & 3 & 3 \\
\hline 刺旋花 Convolvulus tragacanthoides & 0 & 1 & 1 & 0 & 0 & 0 & 3 & 3 & 0 & 0 & 0 & 0 & 0 & 3 & 2 \\
\hline 银灰旋花 Convolvulus ammannii & 0 & 1 & 1 & 0 & 0 & 0 & 3 & 3 & 0 & 0 & 0 & 0 & 0 & 2 & 2 \\
\hline 沙引草 Messerschmidia rosmarinifolia & 0 & 1 & 1 & 0 & 0 & 1 & 2 & 2 & 1 & 0 & 0 & 0 & 0 & 2 & 2 \\
\hline 紫筒草 Stenosolenium saxatile & 1 & 1 & 1 & 0 & 0 & 1 & 2 & 3 & 1 & 0 & 0 & 0 & 0 & 3 & 3 \\
\hline 灰毛假紫草 Arnebia fimbriata & 1 & 1 & 1 & 0 & 0 & 1 & 2 & 2 & 1 & 0 & 0 & 0 & 0 & 3 & 3 \\
\hline 蒙古莸 Caryopteris mongholica & 1 & 1 & 1 & 1 & 1 & 0,1 & 2 & 3 & 1 & 0 & 0 & 0 & 0 & 2 & 2 \\
\hline
\end{tabular}


表1 (续) Table 1 (continued)

\begin{tabular}{|c|c|c|c|c|c|c|c|c|c|c|c|c|c|c|c|}
\hline 种名 Species name & $\begin{array}{c}\text { Cell } \\
\text { shape }\end{array}$ & $\begin{array}{l}\mathrm{CW} \\
\text { ada }\end{array}$ & $\begin{array}{l}\text { CW } \\
\text { aba }\end{array}$ & $\begin{array}{c}\text { Papillae } \\
\text { ada }\end{array}$ & $\begin{array}{c}\text { Papillae } \\
\text { aba }\end{array}$ & $\begin{array}{c}\text { Trichome } \\
\text { type }\end{array}$ & $\begin{array}{c}\text { Trichome } \\
\text { ada }\end{array}$ & $\begin{array}{c}\text { Trichome } \\
\text { aba }\end{array}$ & $\begin{array}{c}\text { Wax } \\
\text { ada }\end{array}$ & $\begin{array}{c}\text { Wax } \\
\text { aba }\end{array}$ & $\begin{array}{c}\text { St } \\
\text { type }\end{array}$ & $\begin{array}{l}\text { St-s } \\
\text { ada }\end{array}$ & $\begin{array}{l}\text { St-s } \\
\text { aba }\end{array}$ & $\begin{array}{c}\text { St } \\
\text { ada }\end{array}$ & $\begin{array}{c}\text { St } \\
\text { aba }\end{array}$ \\
\hline 冬青叶兔唇花 Lagochilus ilicifolius & 1 & 1 & 1 & 0 & 0 & 1 & 1 & 1 & 1 & 1 & 0 & 0 & 0 & 3 & 3 \\
\hline 香青兰 Dracocephalum moldavica & 1 & 1 & 1 & 0 & 0 & 1 & 2 & 1 & 1 & 1 & 0 & 0 & 0 & 2 & 3 \\
\hline 百里香 Thymus mongolicus & 1 & 1 & 1 & 0 & 0 & 1 & 1 & 1 & 1 & 1 & 0 & 0 & 0 & 2 & 2 \\
\hline 黒果枸杞 Lycium ruthenicum & 1 & 1 & 0 & 0 & 0 & - & 0 & 0 & 1 & 1 & 0 & 1 & 1 & 2 & 2 \\
\hline 刺疮㾑 Olgaea tangutica & 0 & 1 & 1 & 0 & 0 & 0 & 3 & 1 & 0 & 1 & 0 & 0 & 1 & 2 & 2 \\
\hline 油蒿 Artemisia ordosica & 0 & 1 & 0 & 0 & 0 & 0 & 1 & 1 & 1 & 1 & 2 & 1 & 1 & 3 & 3 \\
\hline 差巴嘎蒿 Artemisia halodendron & 0 & 1 & 0 & 0 & 0 & 0 & 3 & 3 & 0 & 0 & 0 & 0 & 0 & 2 & 2 \\
\hline 白莲蒿 Artemisia sacrorum & 0 & 1 & 1 & 0 & 0 & 1 & 3 & 3 & 0 & 0 & 0 & 0 & 0 & 3 & 3 \\
\hline 白沙蒿 Artemisia blepharolepis & 1 & 1 & 1 & 0 & 0 & 1 & 1 & 1 & 1 & 1 & 0 & 0 & 0 & 3 & 3 \\
\hline 乌丹蒿 Artemisia wudanica & 1 & 0 & 0 & 0 & 0 & 0 & 1 & 1 & 0 & 0 & 0 & 0 & 0 & 3 & 3 \\
\hline 籽蒿 Artemisia sphaerocephala & 1 & 1 & 1 & 0 & 0 & 1 & 1 & 1 & 1 & 1 & 0 & 0 & 0 & 3 & 3 \\
\hline $\begin{array}{l}\text { 中亚紫苑木 Asterothamnus centrali- } \\
\quad \text { asiaticus }\end{array}$ & 0 & 1 & 1 & 0 & 0 & 0 & 3 & 2 & 1 & 1 & 0 & 0 & 0 & 2 & 2 \\
\hline 花花柴 Karelinia caspia & 0 & 1 & 1 & 0 & 0 & 1 & 1 & 1 & 1 & 0 & 0 & 1 & 1 & 3 & 3 \\
\hline 星毛短舌菊 Brachanthemum pulvinatum & 1 & 1 & 0 & 0 & 0 & 0,1 & 2 & 2 & 1 & 1 & 0 & 0 & 0 & 2 & 2 \\
\hline 灌木亚菊 Ajania fruticulosa & 1 & 1 & 1 & 0 & 0 & 0,1 & 2 & 2 & 0 & 0 & 0 & 0 & 0 & 1 & 1 \\
\hline 著状亚菊 Ajania achilloides & 1 & 1 & 1 & 0 & 0 & 0 & 3 & 3 & 0 & 0 & 0 & 0 & 0 & 2 & 2 \\
\hline
\end{tabular}

Cell shape, 表皮细胞形态: 0, 多边形; 1, 不规则形。CW ada和CW aba, 上、下表皮细胞垂周壁式样: 0, 直线形; 1, 弯曲形。Papillae ada和Papillae aba, 上、下表皮乳突: 0 , 无; 1 , 有。Trichome type, 表皮毛是否具有腺体: 0 , 无; 1 , 有。Trichome ada和Trichome aba, 上、下表皮线毛数量: 0 , 无线毛: 1, 1-10 个 $\cdot \mathrm{mm}^{-2} ; 2,10-50$ 个 $\cdot \mathrm{mm}^{-2} ; 3$, 多于 50 个 $\cdot \mathrm{mm}^{-2}$ 。Wax ada和Wax aba, 上、下表皮角质膜蜡质层: 0 , 无; 1 , 有。St type, 主要气孔类型: 0 , 不规则型; 1 , 不 等型; 2 , 平列型; 3 , 哑铃型。St-s ada和St-s aba, 上、下表皮气孔是否下陷: 0 , 不下陷; 1 , 下陷。St ada和St aba, 上、下表皮气孔数量: 0 , 无; 1 , 少于 100 个 $\cdot \mathrm{mm}^{-2} ; 2,100-200$ 个 $\cdot \mathrm{mm}^{-2} ; 3$, 多于 200 个 $\cdot \mathrm{mm}^{-2}$ 。-表示不破坏真实形态结构的情况下观察不到线毛或气孔。线毛或气孔数量是通过扫描电镜一个视 野的数量转换成每 $\mathrm{mm}^{2}$ 的数量计算得到, 其平均数是通过 10 片随机选取的叶片表皮的数量平均得到。

Cell shape, the shape of epidermal cells on adaxial and abaxial epidermis: 0, polygonal shape; 1 , irregular shape. CW ada and CW aba, anticlinal cell walls of adaxial and abaxial epidermal cells: 0 , straight; 1 , sinuous. Papillae ada and Papillae aba, papillae on adaxial and abaxial epidermal cells: 0 , absent; 1 , present. Trichome type, trichomes have glandular: 0 , non-glandular trichomes; 1 , glandular trichomes. Trichome ada and Trichome aba, number of trichomes on adaxial and abaxial epidermis: 0 , trichomes not present in examined area; $1,1-10$ trichomes $\cdot \mathrm{mm}^{-2} ; 2,10-50$ trichomes $\cdot \mathrm{mm}^{-2} ; 3$, more than 50 trichomes $\cdot \mathrm{mm}^{-2}$. Wax ada and Wax aba, wax flakelets on adaxial and abaxial epidermis: 0 , absent; 1 , present. St type, predominant stomata type: 0 , anomocytic; 1 , anisocytic; 2, paracytic; 3, graminaceous. St-s, ada and aba, sunken stomata on adaxial and abaxial epidermis: 0, not sunken stomata; 1, sunken stomata. St ada and St aba, number of stomata on adaxial and abaxial epidermis: 0 , no stomata; 1 , less than $100 \cdot \mathrm{mm}^{-2} ; 2,100-200 \cdot \mathrm{mm}^{-2} ; 3$, more than $200 \cdot \mathrm{mm}^{-2}$. - , no trichomes or stomata were observed in the natural micro-structure. The numbers of trichomes or stomata in a visual field was measured by scanning electron microscopy and converted to number per square millimeter, and the average numbers of trichomes or stomata per square millimeter were calculated on the leaf surface of 10 random leaf splices.
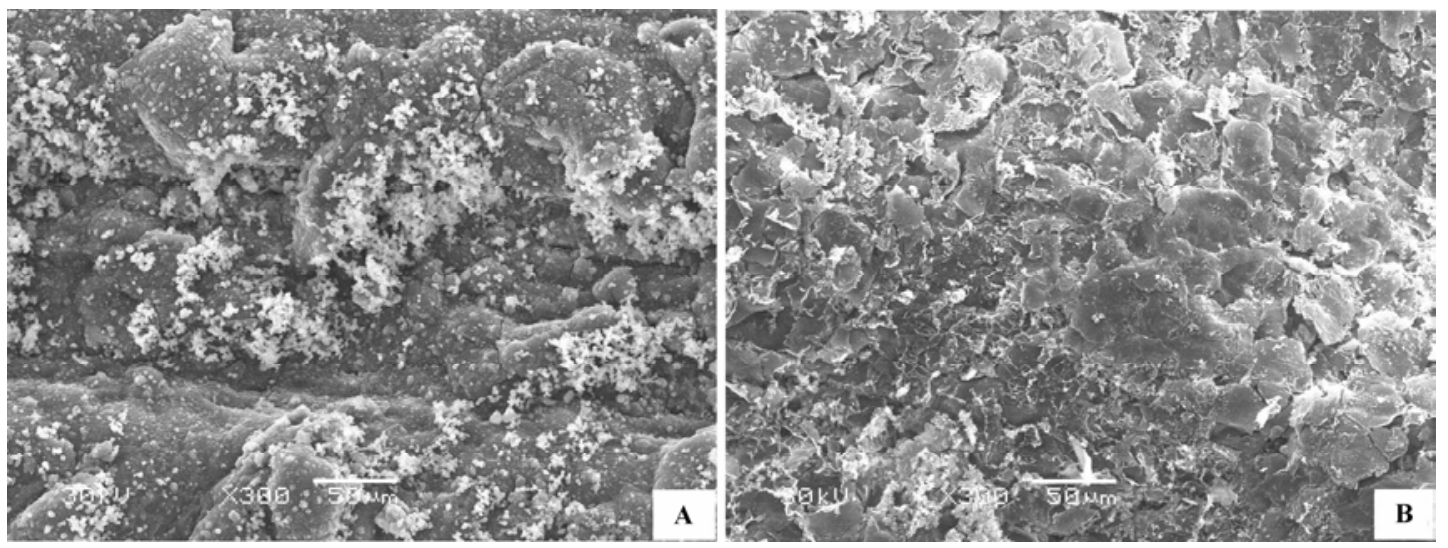

图1 荒漠植物叶片(同化枝)表皮微形态结构特征。A, 膜果麻黄。 $\mathbf{B}$, 霸王。

Fig. 1 Micromorphological and structural characteristics of leaf (or assimilation branches) epidermis of desert plants. A, Ephedra przewalskii. B, Zygophyllum xanthoxylon.

生在一起(图4)。代表植物有: 蒙古获(Caryopteris mongholica)(图4A)、香青兰(Dracocephalum moldavica)(图4B)、白莲蒿(Artemisia sacrorum)(图4C)、 星毛短舌菊(Brachanthemum pulvinatum)(图4D)等。

(5)上下表面完全异面 上表皮被线毛, 下表皮
主要被粗䊁痂状、壳状或膜片状蜡质层。代表植物 主要是柳属(Salix)植物(图5), 如旱柳(Salix capitata) (图5A、5B)、黄柳(Salix gordejevii)(图5C、5D)、乌 柳(Salix microstachya)、沙柳(Salix psammophila)等。

(6)气孔器集中于下表面 上表皮光滑, 无气孔

www.plant-ecology.com 

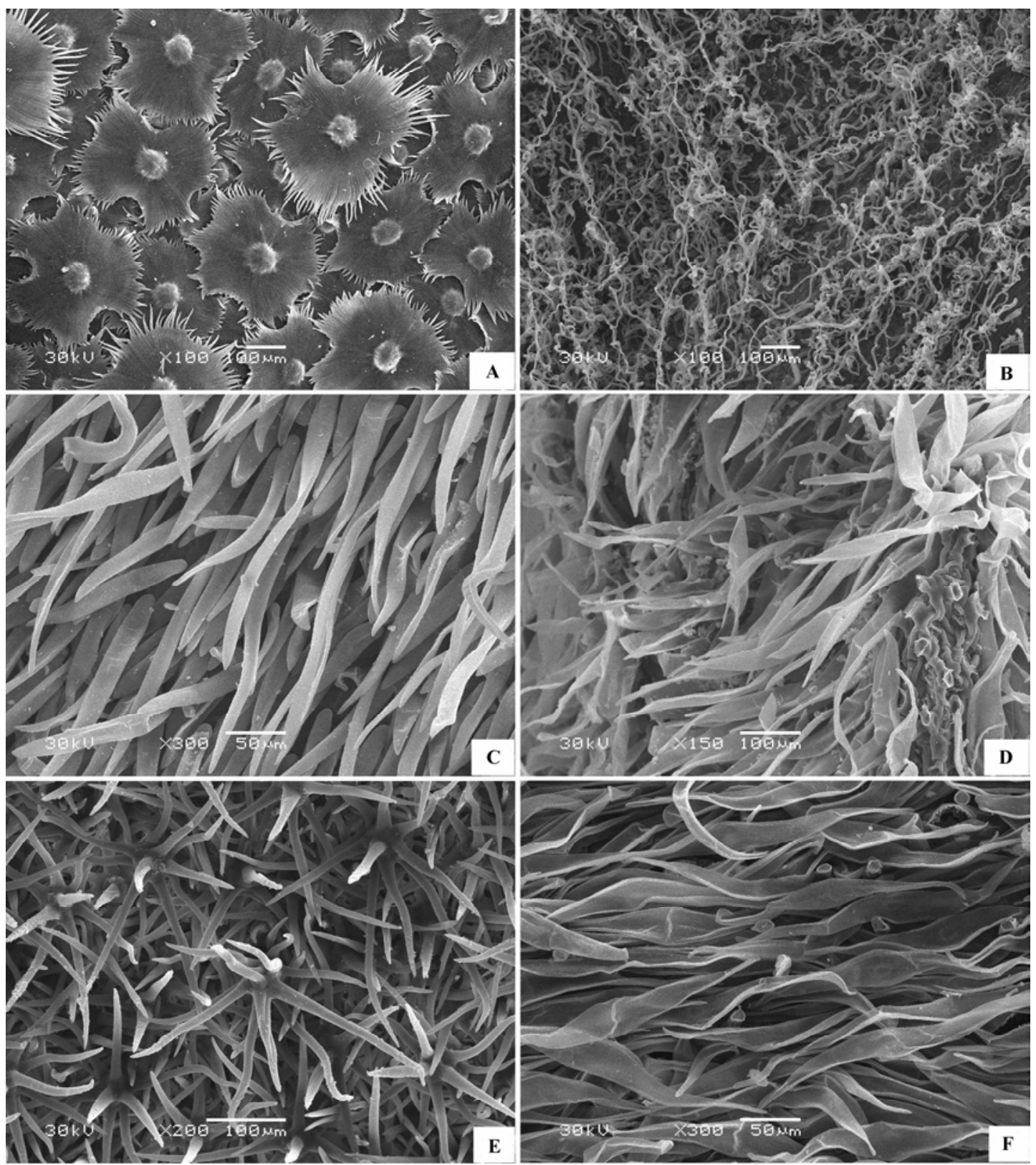

图2 荒漠植物叶片表皮微形态结构特征。 $\mathbf{A}$, 沙柊。 $\mathbf{B}$, 刺疮㾂。 $\mathbf{C}$, 唐古特白刺。 $\mathbf{D}$, 珍珠猪毛菜。 $\mathbf{E}$, 驼线㢣。 $\mathbf{F}$, 著状亚菊。 Fig. 2 Micromorphological and structural characteristics of leaf epidermis of desert plants. A, Elaeagnus angustifolia. B, Olgaea tangutica. C, Nitraria tangutorum. D, Salsola passerina. E, Ceratoides latens. F, Ajania achilloides.
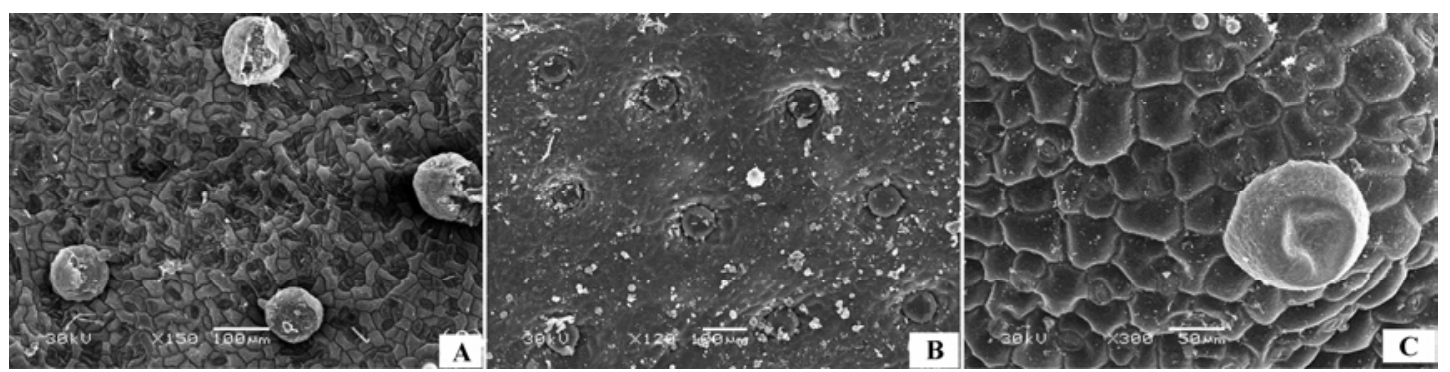

图3 荒漠植物叶片表皮微形态结构特征。A, 甘草。B, 百里香。C, 单脉大黄。

Fig. 3 Micromorphological and structural characteristics of leaf epidermis of desert plants. A, Glycyrrhiza uralensis. B, Thymus mongolicus. C, Rheum uninerve. 


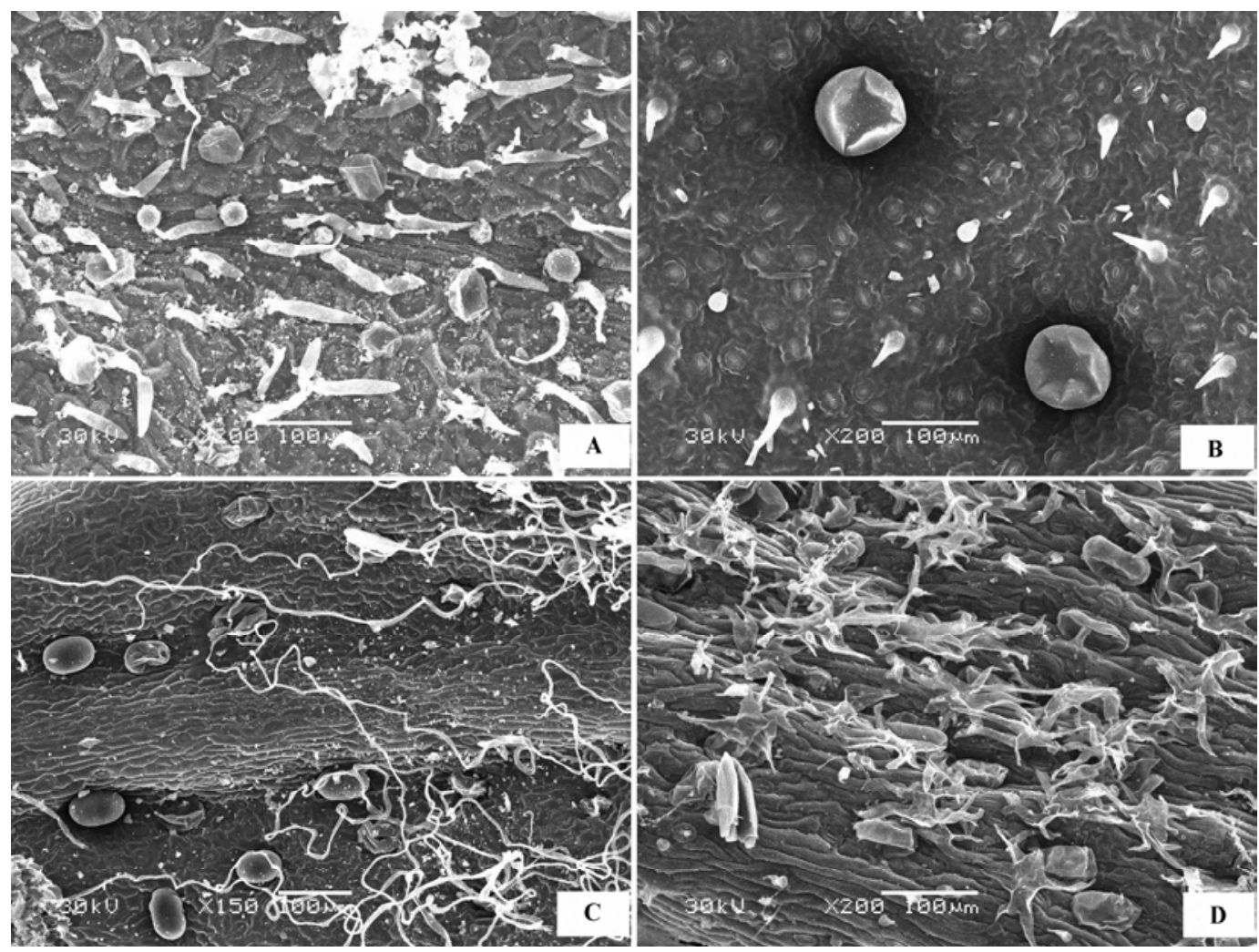

图4 荒漠植物叶片表皮微形态结构特征。A, 蒙古获。 $\mathrm{B}$, 香青兰。C, 白莲蒿。 $\mathrm{D}$, 星毛短舌菊。

Fig. 4 Micromorphological and structural characteristics of leaf epidermis of desert plants. A, Caryopteris mongholica. B, Dracocephalum moldavica. C, Artemisia sacrorum. D, Brachanthemum pulvinatum.
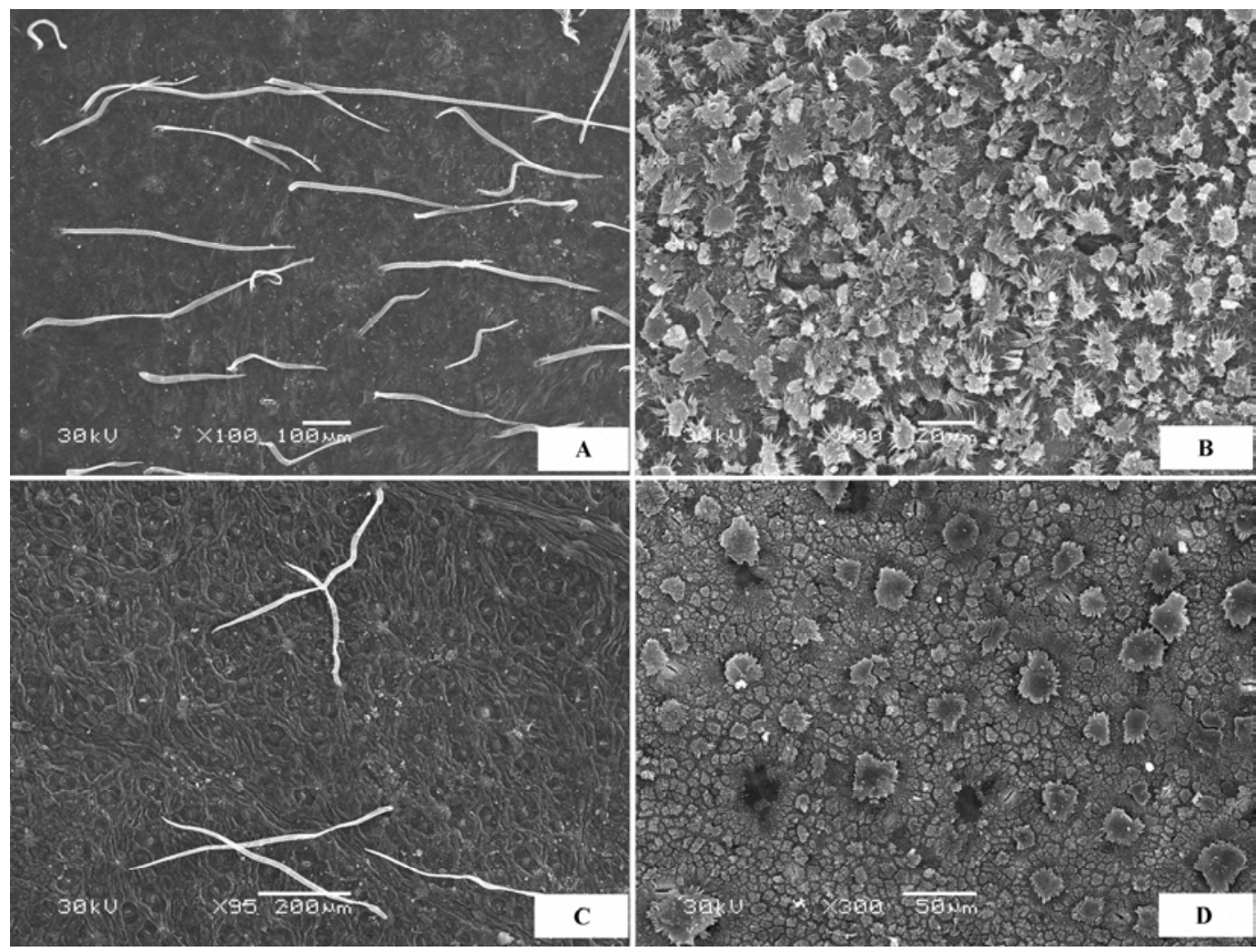

图5 荒漠植物叶片表皮微形态结构特征。A, 旱柳上表皮。 $\mathbf{B}$, 旱柳下表皮。C, 黄柳上表皮。D, 黄柳下表皮。

Fig. 5 Micromorphological and structural characteristics of leaf epidermis of desert plants. A, Adaxial surface of Salix capitata. B, Abaxial surface of Salix capitata. C, Adaxial surface of Salix gordejevii. D, Abaxial surface of Salix gordejevii. 
器, 下表皮有高密度气孔器, 代表植物有蒙古扁桃 (Prunus mongolica)(图6A、6B)、柄扁桃(Prunus pedunculata)、杜柳(Periploca sepium)(图6C、6D)等。

(7)疮状 表皮无线毛附属物, 表皮细胞突起的 宽度大于高度, 基部不收缩(图7)。代表植物有合头 草(Sympegma regelii)(图7A)、芦苇(Phragmites com-

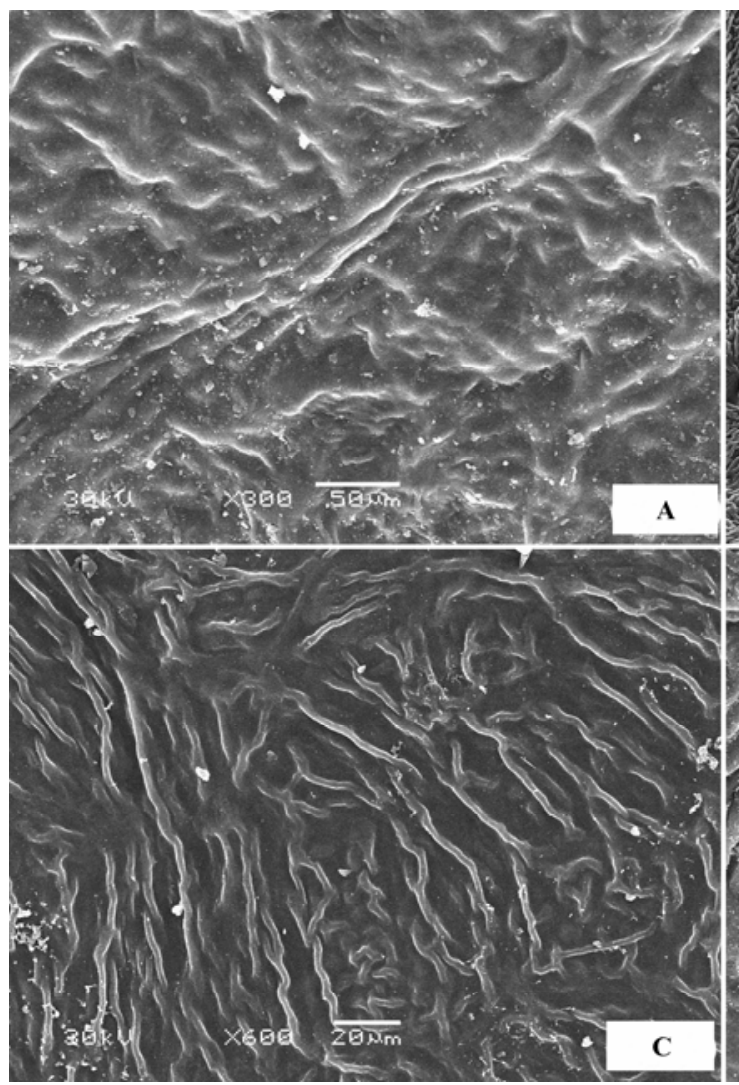

munis)(图7B)等。

(8)瘤状 表皮无线毛或有少量线毛, 表皮细胞 突起的高度大于或等于宽度, 顶部半圆形(图8)。代 表植物有小獐毛(Aeluropus littoralis)(图8A)、罗布麻 (Apocynum venetum)(图8B)等。

(9)光滑型 荒漠植物中为数不多的植物叶片

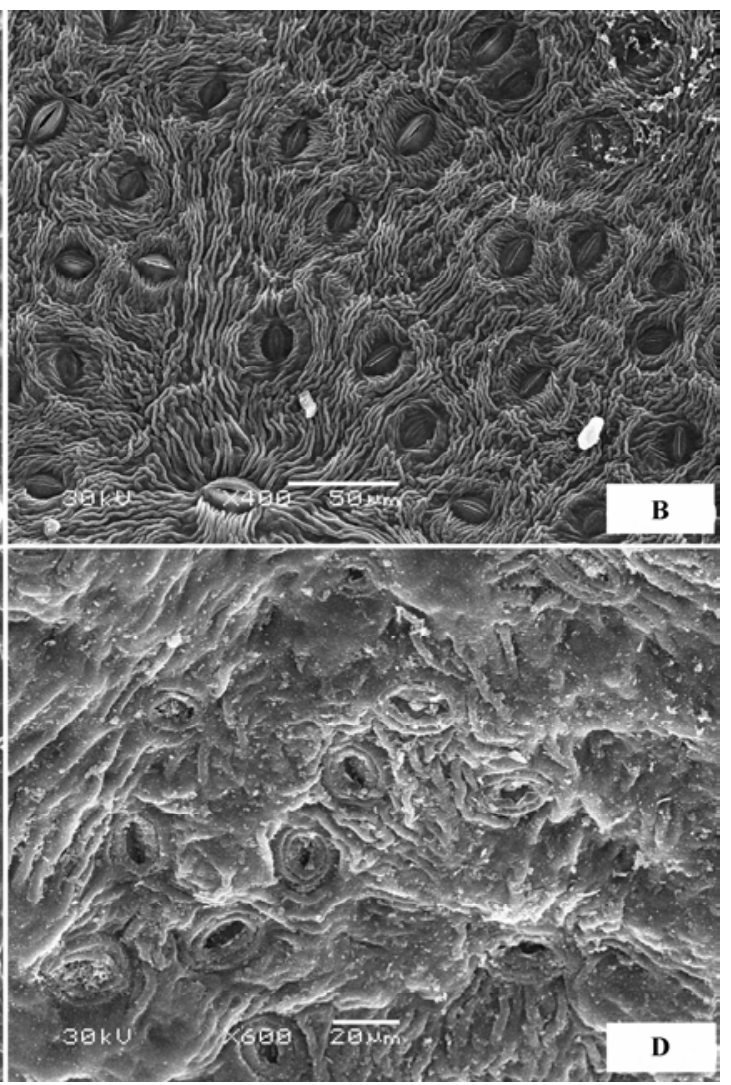

图6 荒漠植物叶片表皮微形态结构特征。A, 蒙古扁桃上表皮。 $\mathbf{B}$, 蒙古扁桃下表皮。C, 杜柳上表皮。

Fig. 6 Micromorphological and structural characteristics of leaf epidermis of desert plants. A, Adaxial surface of Prunus mongolica. B, Abaxial surface of Prunus mongolica. C, Adaxial surface of Periploca sepium. D, Abaxial surface of Periploca sepium.
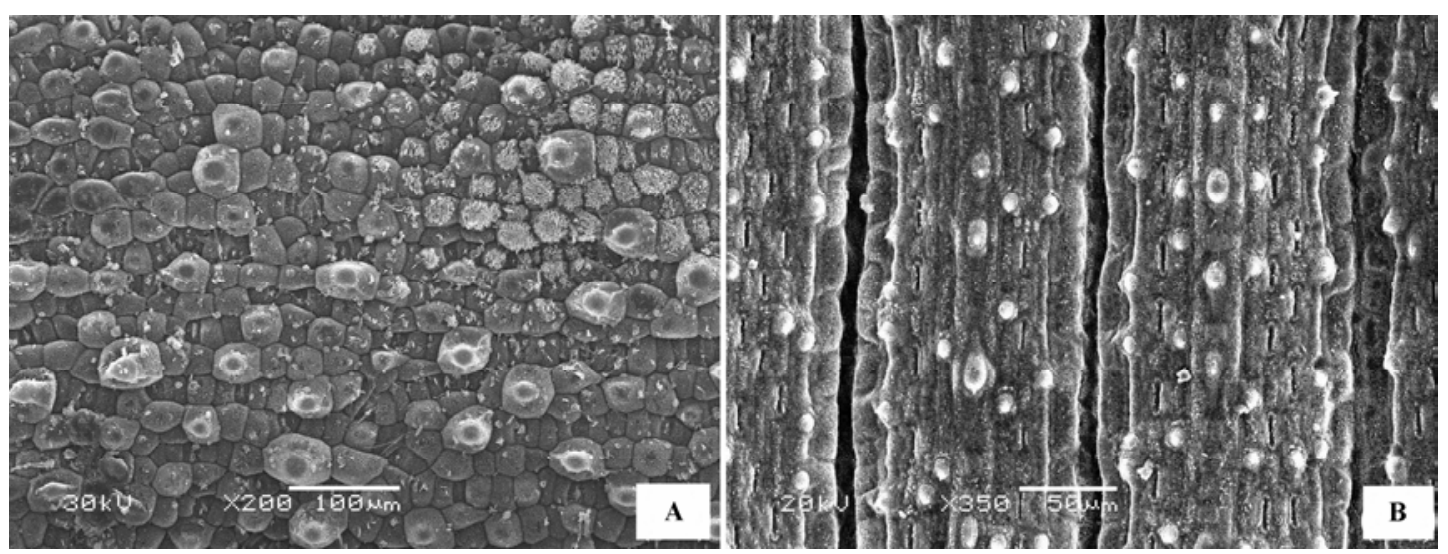

图7 荒漠植物叶片表皮微形态结构特征。A, 合头草。B, 芦苇。

Fig. 7 Micromorphological and structural characteristics of leaf epidermis of desert plants. A, Sympegma regelii. B, Phragmites communis. 
表面相对比较光滑, 气孔密度较高, 气孔深陷或不 下陷，没有其他附属物。代表植物有沙葱(Allium mongolicum)(图9A)、沙木蓼(Atraphaxis bracteata)、 骆驼蓬属(Peganum)植物如多裂骆驼蓬(Peganum multisectum)(图9C)、牛心朴子(Cynanchum komarovii)(图9B)、乌丹蒿(Artemisia wudanica)(图9D)、 籽高(Artemisia sphaerocephala)、瓦松(Orostachys fimbriatus)等。

(10)褶皱状 叶片表面形成凸凹不平、大小不 等、形状不同的皱褶，气孔器穴居于皱褶凹陷处，表 皮无线毛附属物。代表植物有短叶假木贼(Anabasis brevifolia)、梭梭(Haloxylon ammodendron)(图10A)、 木本猪毛菜(Salsola arbuscula)、猪毛菜(Salsola collina)(图10B)、黑果枸杞(Lycium ruthenicum)、红

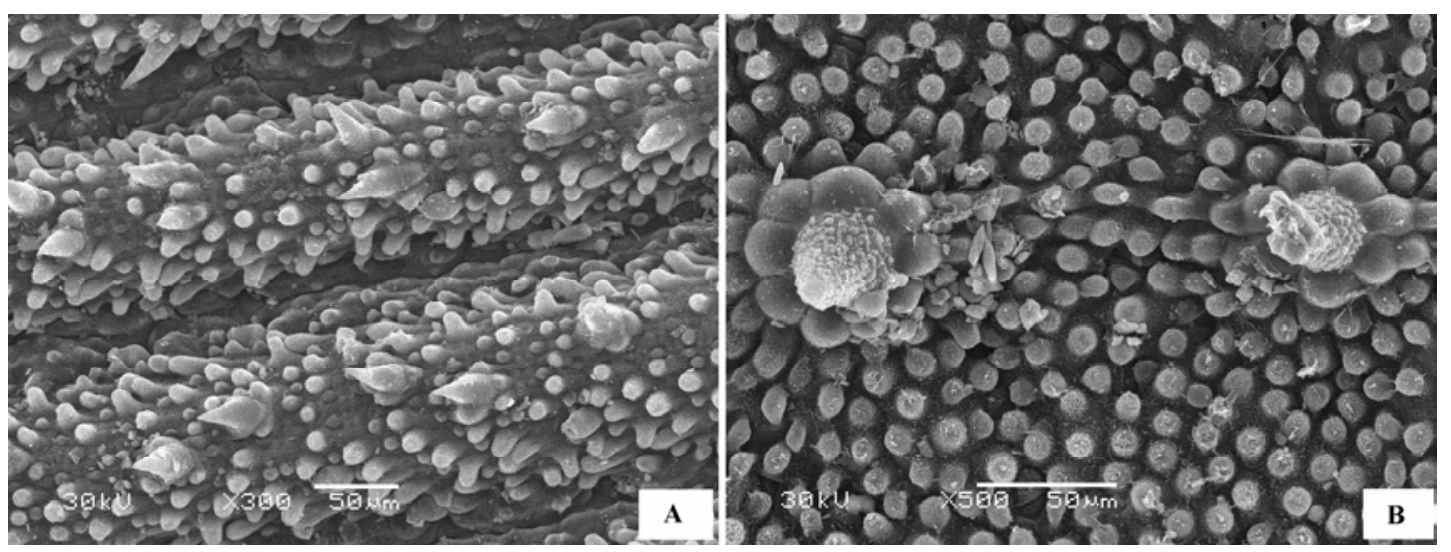

图8 荒漠植物叶片表皮微形态结构特征。 $\mathbf{A}$, 小獐毛。 $\mathbf{B}$, 罗布麻。

Fig. 8 Micromorphological and structural characteristics of leaf epidermis of desert plants. A, Aeluropus littoralis. B, Apocynum venetum.
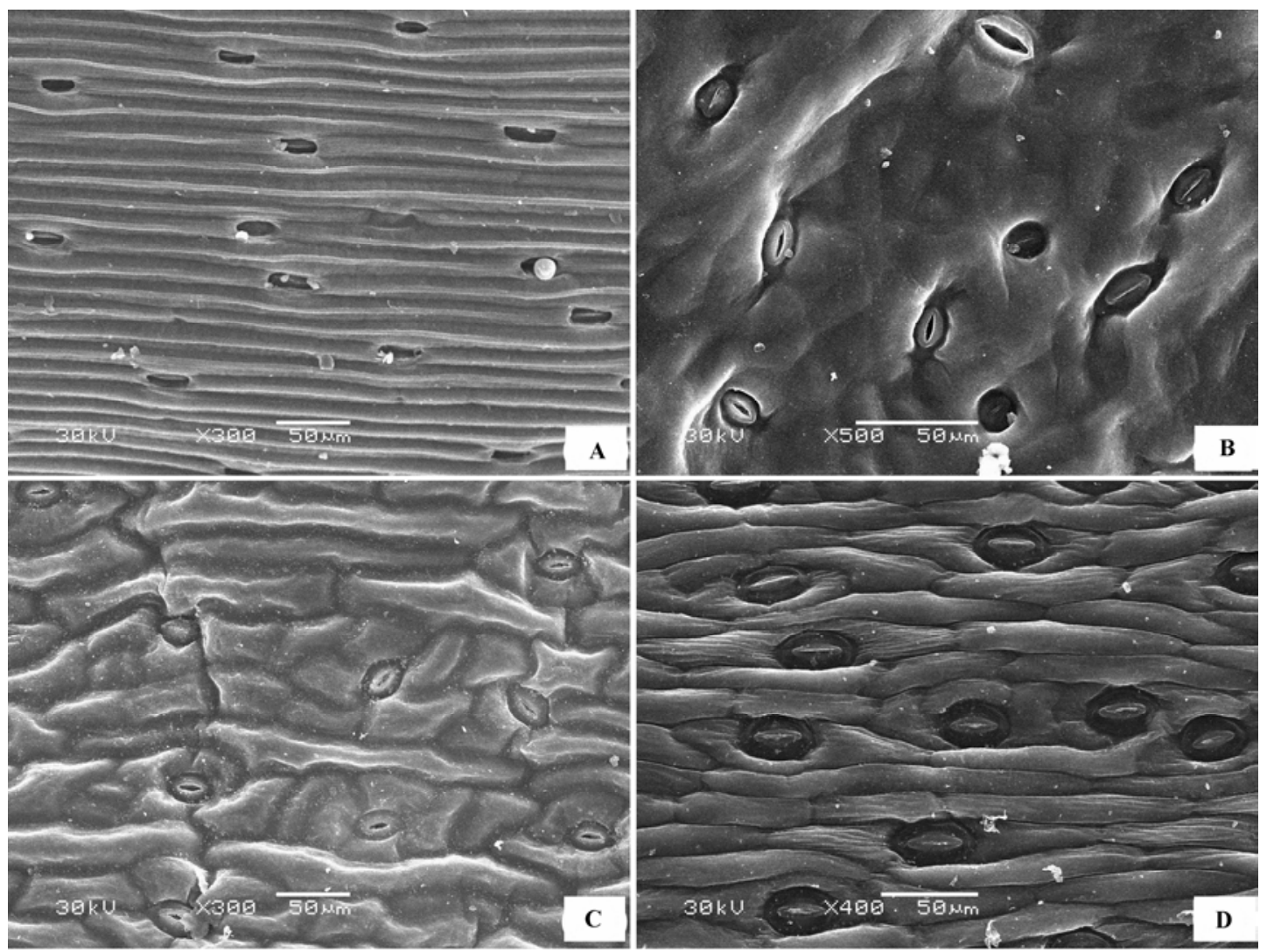

图9 荒漠植物叶片(或同化枝)表皮微形态结构特征。A, 沙葱。 $\mathbf{B}$, 牛心朴子。C, 多裂骆驼蓬。 D, 乌丹蒿。

Fig. 9 Micromorphological and structural characteristics of leaf (or assimilation branches) epidermis of desert plants. A, Allium mongolicum. B, Cynanchum. komarovii. C, Peganum multisectum. D, Artemisia wudanica. 

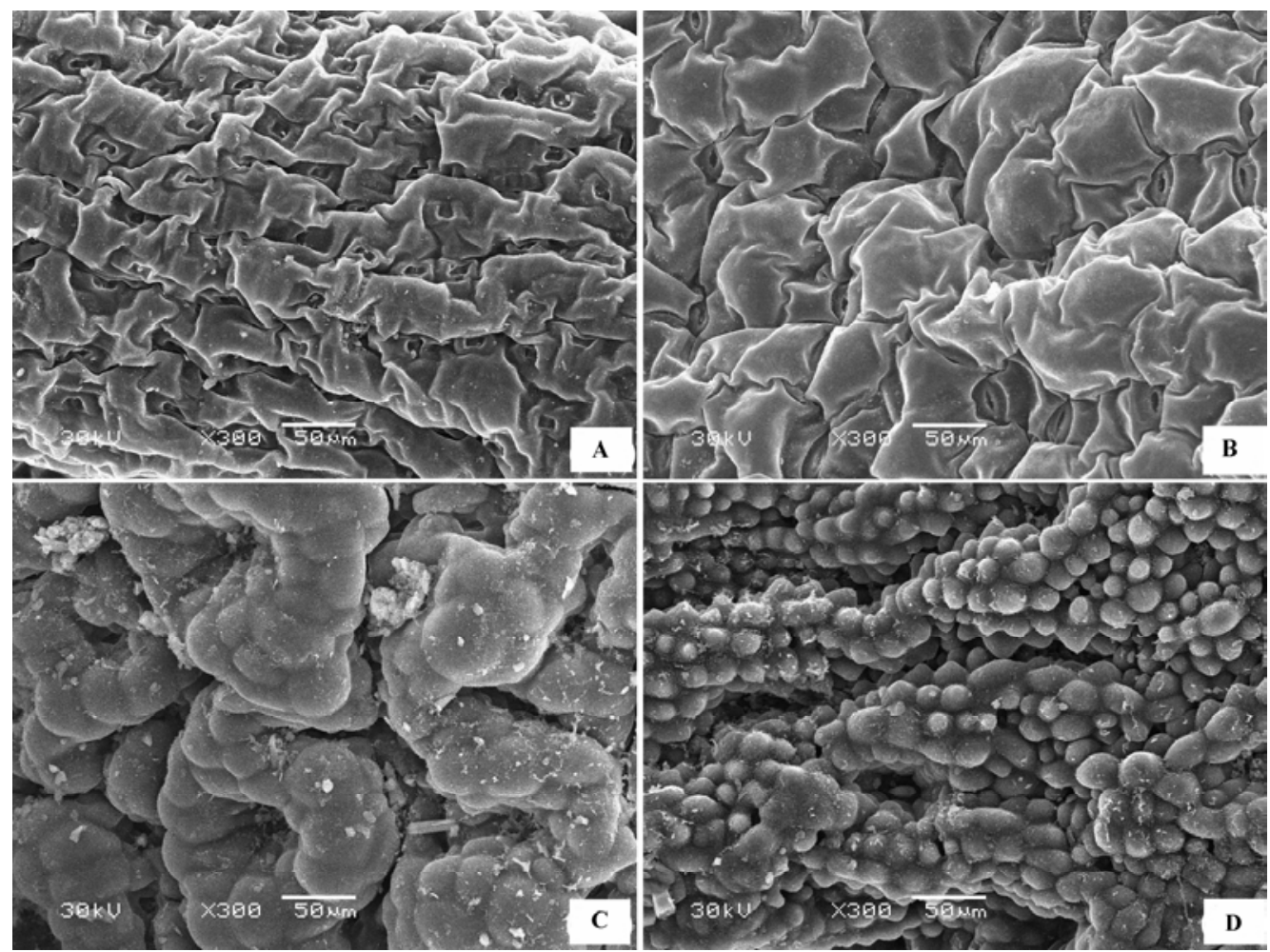

图10 荒漠植物叶片(或同化枝)表皮微形态结构特征。A, 梭梭。 $\mathbf{B}$, 猪毛菜。C, 红砂。 $\mathbf{D}$, 柽柳。

Fig. 10 Micromorphological and structural characteristics of leaf (or assimilation branches) epidermis of desert plants. A, Haloxylon ammodendron. B, Salsola collina. C, Reaumuria soongorica. D, Tamarix chinensis.

砂属(Reaumuria)(图10C)和柽柳属(Tamarix)(图10D) 的植物等。

(11)多种附属物混生状 多数片状叶片的荒漠 植物叶表皮都有线毛、蜡质晶体等多种附属物混生, 但叶片表皮细胞形态清晰可见。代表植物有雾冰萩 (Bassia dasyphylla)(图11A)、沙米(Agriophyllum squarrosum)(图 11B)、骆驼刺 (Alhagi sparsifolia)(图 11C)、兴安胡枝子(Lespedeza davurica)、部分锦鸡 儿属(Caragana)植物如荒漠锦鸡儿(Caragana roborovskyi)(图11D)、岩黄芪属(Hedysarum)植物、油蒿 (Artemisia ordosica)、差巴嘎蒿(Artemisia halodendron)、绵刺(Potaninia mongolica)、猫头刺(Oxytropis aciphylla)(图11E)、半日花(Helianthemum songaricum)(图11F)、花花柴(Karelinia caspia)(图11G)、 中亚紫苑木(Asterothamnus centrali-asiaticus)(图11 $\mathrm{H})$ 等。

\section{3 荒漠植物叶片(或同化枝)表皮微形态抗逆适应}

\section{主要类型}

植物叶片形态结构与抗逆性关系的研究表明, 植物叶片小、表皮附属物密度大、且表皮皱缩程度 高, 则抗旱性强(王勋陵和马骥, 1999; 周智斌和李
培军, 2002; Bargel et al., 2004; 迟丽华和宋凤斌, 2006; Adebowale et al., 2014; 赵小仙等, 2014; 朱广 龙等, 2016)。通过比较荒漠植物叶片(或同化枝)的表 皮微形态结构, 可以从表皮细胞形态, 表皮附属物 如线毛、蜡质、气孔等的形态、密度、结构和分布 特征来进行环境适应性分析。根据表皮微形态结构 和附属物与抗逆性的关系, 将荒漠植物适应环境胁 迫的表皮微形态分为以下 6 种主要类型。

(1)完全依赖于表皮毛 形态各异的表皮线毛 完全覆盖叶片上下表面, 阻止水分蒸腾和反射强光, 同时具有吸附空气中的水汽的功能。代表性植物为 表皮微形态结构基本类型(2)中的沙本、柠条锦鸡 儿、珍珠猪毛菜、蒙古获、蓄状亚菊等。

(2)完全依赖于角质层蜡质 不同形态的蜡质 层完全覆盖叶片表面, 表面粗糙, 阻止水分蒸腾和 反射强光。代表性植物为表皮微形态结构基本类型 (1)中的膜果麻黄、霸王、灌木铁线莲等。

(3)依赖于表皮凹凸结构 表皮细胞堆积呈凹 凸状, 气孔深陷凹槽内, 气孔指数很小, 阻止蒸腾。 代表性植物为表皮微形态结构基本类型(10)中的红 砂(Reaumuria soongorica)、柽柳(Tamarix chinensis)、 


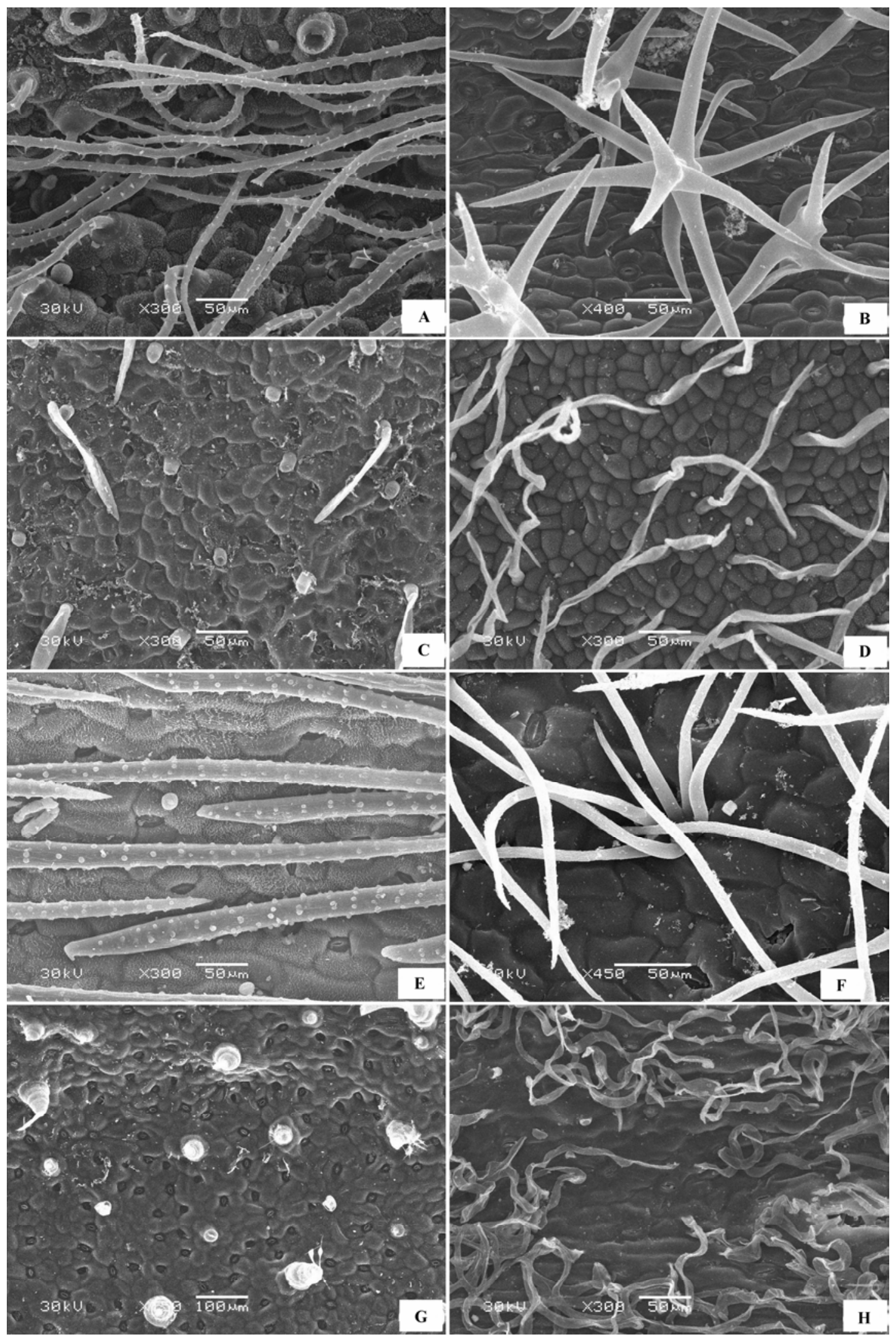

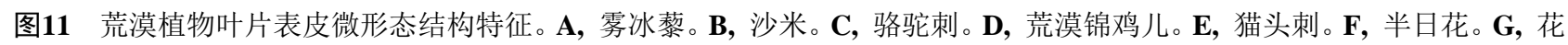
花柴。H, 中亚紫苑木。

Fig. 11 Micromorphological and structural characteristics of leaf epidermis of desert plants. A, Bassia dasyphylla. B, Agriophyllum squarrosum. C, Alhagi sparsifolia. D, Caragana roborovskyi. E, Oxytropis aciphylla. F, Helianthemum songaricum. G, Karelinia caspia. H, Asterothamnus centrali-asiaticus. 
短叶假木贼等。

(4)依赖于表面突起 表面有大量的形态各异 的凸起, 增加叶表面积, 气孔密度相对较低, 减少 蒸腾, 增强吸收水汽的功能。代表性植物为表皮微 形态结构基本类型(7)、(8)中的罗布麻、小獐毛、芦 苇等。

(5)依赖于表皮混生附属物 各种表皮附属物 混生, 多数植物表皮线毛不完全覆盖表面, 有明显 的角质膜蜡质片层结构, 气孔密度较高, 增强了各 种附属物协调抵御逆境的能力。代表性植物为表皮 微形态结构基本类型(4)、(5)、(11)中的沙米、骆驼 刺等。

(6)上表皮异化 上表面气孔指数为 0 , 减少气 孔性水分散失, 并增强对强光的反射。代表性植物 为表皮微形态结构基本类型(6)中的蒙古扁桃、柄扁 桃、杜柳等。

这6种主要适应类型植物的抗旱性大小需根据各 自植物微形态结构对抗旱性的贡献进行统计分析。

\section{3 讨论}

荒漠植物由于长期适应所生长的自然环境, 发 展了一套最适宜自身生长发育的形态结构特征, 并 采取各种途径来抵御或忍耐干旱胁迫对它的影响, 因而具有一定程度的耐旱性。这种耐旱性是一种复 合性状, 包括植物的形态结构特征、水分生理特征、 生理生化反应、组织细胞、光合器官以及原生质结 构等特征的综合反映(Klich, 2000; Chaves et al., 2003; Ogle \& Reynolds, 2004)。不同的荒漠植物对水 分和不利环境的适应和耐受程度不同, 适应方式多 种多样, 按照不同的分类标准, 荒漠植物有多种适 应类型。通常的分类标准包括耐旱程度、耐旱方式、 叶片形态、生活史、光合碳代谢途径等(赵哈林, 2012)。各种类型的植物又有各自的适应特征。本研 究是针对我国干旱半干旱区荒漠植物叶表皮微形态 结构特征的综合分析, 主要集中于该区域的建群种 灌木物种。根据荒漠植物叶表皮微形态基本结构特 征和表皮附属物的类型与数量, 将荒漠植物表皮微 形态类型直观地划分为 11 种, 而将抗逆适应微形态 结构划分为6种类型。荒漠植物叶表皮微形态结构类 型复杂, 反映了植物自身的遗传特性及其与环境的 密切关系。植物叶片表皮微形态主要由遗传因素决 定, 但表皮附属物线毛数量, 蜡质形态与厚度, 气
孔的形态、密度以及分布特征等与环境因子密切相 关, 是植物对环境的响应(Barthlott, 1981; Casson \& Hetherington, 2010; Ghahremaninejad et al., 2012)。因 此, 基于这些表皮主要附属物特征对荒漠植物的表 皮微形态类型和抗逆适应类型进行划分, 能够从微 观形态结构特征进一步揭示物种的亲缘关系和表皮 微形态结构的生态适应意义。

\section{1 荒漠植物叶表皮微形态结构的多样性及其亲 缘关系}

荒漠植物叶表皮微形态结构在不同分类等级上 表现出丰富的多样性, 深刻地反映了植物的亲缘关 系, 不同程度地揭示了它们之间错综复杂的系统演 化关系。叶片表皮微形态结构基本特征根据表皮细 胞形态结构和表皮附属物类型, 分为病状、瘤状、 皱褶状、相对光滑型、表面完全被毛、表面完全被 蜡质层、不同形态结构的线毛和蜡质层混合覆盖、 上下完全异面以及气孔器集中于下表面等11种类 型, 有些类型还包括若干种亚型。如柳属中观察的 4 种植物, 尽管种及地理分布完全不同, 但它们都为 典型的异面叶, 叶片上下表皮都是完全不同的形 态。上表皮线毛密度较高, 不同的种有不同形态和 密度的线毛; 表皮线毛密度低或不具线毛, 但有柳 属植物特有的角质膜蜡质纹饰(王东超等, 2012; Ghahremaninejad et al., 2012), 如黄柳的痂状蜡质 层、旱柳和乌柳的壳状蜡质层、沙柳的膜片状蜡质 晶体。麻黄属的膜果麻黄、斑子麻黄 (Ephedra rhytidosperma)和草麻黄(Ephedra sinica)中, 3种同化 枝的角质膜蜡质晶体数量依次减少, 斑子麻黄与草 麻黄的表皮形态结构接近, 显示亲缘关系较近。膜 果麻黄表皮粗粘, 完全被蜡质层覆盖。锦鸡儿属 (Caragana) 是豆科蝶形花亚科中较大的一个属, 叶 片上下表皮微形态基本一致, 多数为等面叶。但表 皮毛的形态密度各异, 柠条锦鸡儿、小叶锦鸡儿 (Caragana microphlla)和中间锦鸡儿(Caragana intermedia)同属小叶系, 亲缘关系相近, 表皮毛为柳 叶状, 但线毛密度不同, 柠条锦鸡儿表皮毛完全覆 盖叶面, 小叶锦鸡儿和中间锦鸡儿表皮毛密度较小, 且它们的鳞片状蜡质晶体密度相似, 显示他们之间 更近的亲缘关系, 这与其他分子生物学依据得到的 结果不完全一致(Guo et al., 2008)。究其原因, 主要是 因为这3种锦鸡儿属植物之间由于分布区域重叠或交 叉, 因此存在复杂的基因交流(Ma et al., 2003), 不同 
种的亲缘关系与其分布区域的其他种之间的相互杂 交有关, 甚至出现了杂交过渡态类型, 因而给分类带 来了难题, 单纯某一种分类依据是不能完全决定其 亲缘关系的。荒漠锦鸡儿(Caragana roborovskyi)和卷 叶锦鸡儿(Caragana ordosica)线毛为棒状, 表皮细胞 和蜡质层形态亦相似。短脚锦鸡儿 (Caragana brachypoda)和狭叶锦鸡儿(Caragana stenophylla)表皮 毛为柳叶带乳突型, 上表皮气孔器深陷, 气孔器为不 等型或不规则型, 气孔口三角形或多边形。红花锦鸡 儿(Caragana rosea)为明显不同的类群, 表皮无线毛 结构, 且蜡质层形态不同于以上几种的鳞片状, 而是 紧贴表皮的膜片层结构或颗粒状。

同一种植物可以是单一类型的表皮形态结构, 也可以是复合类型的, 也可能是过渡态的。在同一 个属中可以有一种或数种不同的叶表皮形态结构, 它们之间的形态可能是连续的、渐变的, 也可能是 间断的、区分明显的, 但无一不反映出它们之间存 在的亲缘关系, 揭示它们之间极其复杂的演化关 系。如猪毛菜属(Salsola)植物, 从已观测的 4 种植物 表皮形态结构来看, 珍珠猪毛菜表皮完全被柳叶状 毛, 木本猪毛菜、松叶猪毛菜(Salsola laricifolia)与 猪毛菜表皮无毛, 但表皮细胞形态各异, 猪毛菜的 表皮细胞皱褶状, 气孔器下陷, 松叶猪毛菜表皮细 胞皱褶程度低且气孔不下陷。蒿属(Artermisia)是菊 科的一个大属, 存在着不少分类上的争议, 从已观 测的6种来看, 叶表皮形态结构各自不同, 同属龙蒿 亚属的籽蒿、油蒿和差巴嘎蒿的叶表皮结构为渐变 式的, 籽蒿表皮基本没有表皮毛, 油蒿有少量表皮 毛, 差巴嘎蒿有高密度的表皮毛, 气孔器都不下陷, 但油蒿和籽蒿的表皮细胞形态和气孔器结构相同, 显示了更近的亲缘关系。乌丹蒿表皮有少数线毛, 与油蒿和籽蒿接近, 但表皮细胞形态不同。白沙蒿 (Artermisia blepharolepis)表皮细胞形态和气孔器与 籽蒿相同, 但表皮有大量膜片状和颗粒状蜡质晶体, 表面不光滑。而白莲蒿表皮除了卷丝状毛外, 还有 囊状毛, 为另一种形态结构类型。

另外，按照表皮细胞形态和表皮附属物线毛、 蜡质晶体的特征进行基本形态结构的分类, 多种属 于同一种类型的叶表皮微形态结构特征的植物, 它 们出现在不同的属甚至亲缘关系相距甚远的科中。 如蒙古扁桃和杜柳分别属于蓄薇科和萝藦科, 但两 者叶表皮微形态结构属于同种类型, 上表皮无气孔
器, 下表皮有高密度的气孔器; 唐古特白刺和柠条 锦鸡儿的表皮完全被柳叶状线毛等。不同科属的植 物出现相近的表皮微形态结构, 与它们在相同生境 中的进化过程有关，但它们在表皮细胞形态、气孔 器结构与类型、蜡质层结构等其他微形态结构特征 方面还有明显差异。

植物叶片表皮微形态特征的多样性不仅在很大 程度上表达了遗传的多样性和稳定性, 而且具有重 要的系统学和分类学意义, 有助于一些分类问题的 解决。近年来不少研究发现叶表皮性状在一定程度 上能反映分类群间的系统发生, 可用于科下属间关 系的探讨(Kong et al., 2001)。以骆驼蓬属为例, 1889 年Maxim将多裂骆驼蓬定为骆驼蓬(Peganum harmala)的一个变种Peganum harmala var. multisectum, 1949年Bobr却将其定为独立的种(中国科学院中国 植物志编辑委员会, 1998), 《中国沙漠植物志》亦将 之作为种(刘瑛心, 1987), 但国内外一些学者仍倾向 于将其作为骆驼蓬的一个变种。马骥等 $(1997,2003)$ 结合种子微形态结构和有关化学成分、地理分布等 方面的研究结果, 支持将多裂骆驼蓬作为一个独立 的种处理的观点。叶片表皮微形态实验结果表明: 从粗略的叶表皮微形态基本特征统计来看, 二者基 本特征相同, 但骆驼蓬表皮细胞呈褶皱状, 而多裂 骆驼蓬叶表皮基本光滑, 有明显的区别, 赞成将二 者作为不同的独立种的观点。

综上所述, 荒漠植物叶表皮微形态结构既连续 又间断，既有过渡又有交叉，在不同分类等级上表 现出丰富的多样性, 为植物分类科学的进展及植物 进化提供了丰富的信息资料。

\section{2 荒漠植物叶表皮附属物的生理功能与生态环 境的联系}

大多数荒漠植物叶片的一个显著特点是表皮被 线毛, 叶表皮毛的出现与长期的干旱气候有关, 是 植物对干旱环境的适应特征 (Retamales \& Scharaschkin, 2015)。植物叶片表皮毛分两种: 腺毛 和非腺毛(Werker, 1993; Navarro \& Oualidi, 1999)。 非腺毛的主要功能与植物的防御有关。目前确认的 植物叶片表皮非腺毛具有的生理生态功能主要有: 减轻紫外辐射(Karabourniotis et al., 1992; Gregoriou et al., 2007)、降低边界层的传导(Wuenscher, 1970; Kenzo et al., 2008)、降低叶温(Ehleringer \& Mooney, 1978), 以及减少对太阳辐射的接收(Ehleringer et 
al., 1976)等。这些功能决定了干旱区荒漠植物抗逆 能力的大小。干旱地区的叶表皮毛密度比湿润地区 的高(Smith \& Nobel, 1977; Aronne \& de Micco, 2001), 就单个物种而言, 表皮毛密度与温度和辐射 密切相关(Perez-Estrada et al., 2000)。在热带雨林树 种中, 浓密的表皮毛很少见(Turner, 2001), Roth (1984)调查的250种树中仅有15种有较厚的表皮毛, 且较厚的表皮毛一般在干旱、高温和强辐射条件下 产生。而在干旱半干旱的荒漠区, 大多数植物都具 有浓密的表皮毛。显然, 荒漠植物叶上密生的表皮 毛对于植物的生活有重要的意义。从Ehleringer等 (1976)、Ehleringer和Bjorkman (1978)、Ehleringer和 Mooney (1978)研究的荒漠灌木Encelia farinosa的叶 表皮毛对叶片光谱特性和光合、蒸腾等生理活动的 影响来看, 沙漠毒菊在不同生长季生长的叶片具有 不同数量的表皮毛, 表皮毛的变化足够使叶片对光 合有效辐射的吸收从 $81 \%$ 降到 $29 \%$, 对总的太阳辐 射的吸收从 $46 \%$ 降到 $16 \%$, 而亲缘关系较近却没有 表皮毛的同属物种Encelia californiea的有效光合辐 射吸收率为 $84 \%$ 。同时, 由于对太阳辐射吸收的减 少, 导致叶面温度和植物蒸螣速率的降低。荒漠环 境气温经常超过 $40{ }^{\circ} \mathrm{C}$, 而植物最适宜的光合温度 是 $25{ }^{\circ} \mathrm{C}$, 当温度超过 $35{ }^{\circ} \mathrm{C}$ 时植物的光合速率会突 降, 但较厚的叶表皮毛能使叶温显著低于气温而接 近光合适宜温度, 同时也避免植物达到叶片致死温 度。但叶表皮毛也有不利的一面, 表皮毛的覆盖降 低了光合速率, 因此同一植物在不同的生境和生长 季长出的叶片会出现表皮毛数量不同的特征, 这也 是植物适应环境的一种权衡策略 (Kenzo et al., 2008)。从本研究中的117种荒漠植物叶表皮特征来 看, 片状叶片基本被有表皮毛, 并有不少叶片的表 皮毛数量较多, 直接增加了叶片的边界层厚度, 个 别植物的上下表皮毛厚度远超于叶片厚度, 如表皮 微形态抗逆适应主要类型的第一类植物中的柠条锦 鸡儿、卷叶锦鸡儿和沙杳等。可见荒漠植物中叶片 表皮毛的作用是相当重要的, 它们不仅能调节植物 的生理功能, 而且可抵御风沙等机械损伤的直接伤 害。这些物种在不同的自然生境中其表皮毛数量亦 不同(数据省略), 说明生态环境深刻地影响着植物 形态结构的形成与变异。

而对于腺毛来说, 其主要作为一个油性物质的 合成、分泌和累积的器官, 有效地防御动物的捕食、
病菌入侵以及物种竞争(Werker, 1993; Wagner et al., 2003; Kremer et al., 2014; Munien et al., 2015)。实际 上, 腺毛也是次生代谢产物的一个独立的细胞工厂 (Tissier, 2012)。腺毛的形态随植物的组织器官和种类 不同而呈多样化, 其形成和分泌的主要油性物质及 其产物组成受遗传和环境两方面的因素控制 (Bosabalidis \& Kofidis, 2002; Shafiee-Hajiabad et al., 2014), 腺毛结构的多样性也可以为植物分类学提供 依据(Gairola et al., 2009; Rusydi et al., 2013)。对117 种荒漠植物叶片表皮扫描发现: 不少旱生植物除具 有非腺体表皮毛外，还同时具有腺毛，并且有些腺 毛体积较大, 如蒙古获、甘草、香青兰、星毛短舌菊、 百里香等。显然, 对于具有腺毛的荒漠植物, 腺毛具 有重要的功能。但目前关于不同植物腺毛的形态、 形成以及功能的研究还很有局限性。那么, 这些腺 毛在植物适应荒漠环境的过程中其形态结构与环境 因子有何关系、主要分泌哪些化学物质、发挥什么 样的功能? 这些问题亟待下一步的深入研究。

荒漠植物叶片的另一个显著特点是表皮有较厚 的角质膜蜡质层。角质膜蜡质层与表皮毛有共同的 功能, 是植物表皮的保护屏障, 主要由长链碳氢化 合物组成(Shepherd \& Wynne, 2006)。叶片对光的反 射由叶面形貌决定, 表皮毛和蜡质层是决定荒漠植 物叶表面形貌的关键。Holmes和Keiller (2002)研究 了45种桉属和伽蓝菜属植物的蜡质叶, 发现蜡质层 对紫外光(330 nm)和光合有效辐射 $(680 \mathrm{~nm})$ 的反射 比各种形态的表皮毛更强, 去除蜡质层通常会减少 对这两种光的反射, 特别是对紫外光的反射, 但对 表皮无蜡质的叶片影响不大。同时不同的物种对不 同波长的光的反射亦不同, 表明蜡质晶体的形态直 接影响着对光的反射, 并且不同温度下的反射强度 也不同, 可见蜡质层对光的反射特性变化很大 (Holmes \& Keiller, 2002)。叶表皮蜡质层参与植物对 水分、盐、低温、污染、机械损伤等多种胁迫响应 的过程, 提高植物对胁迫的抗性(Cameron, 1970; Bargel et al., 2004; Perrone et al., 2013, 2015)。因此, 本研究中117种荒漠植物叶片表皮颗粒状、膜片状、 晶簇状、鳞片状、杆状等各种不同形态的蜡质晶体 既是植物长期适应环境的结果, 也对荒漠植物在严 酷环境中的生长和生存至关重要。总的来说, 这些 植物中灌木的蜡质层密度高于草本, 无表皮毛的叶 片蜡质层密度高于表皮毛覆盖的, 特别是以同化枝 
为主要光合器官和棒状叶片的植物，表皮基本没有 表皮毛覆盖, 主要的附属物是蜡质层, 如麻黄属、沙 拐束属、红砂属的植物等, 弥补了表皮毛的功能。

另外，表面乳突或表皮皱褶，一方面增加了叶 表面积, 另一方面使气孔器能够穴居于凹陷处而避 免强光的直射(Adebowale et al., 2014)。选取的117种 荒漠植物的气孔密度主要集中于 $100-200$ 个 $\cdot \mathrm{mm}^{-2}$, 个别植物的气孔密度相当低, 如红砂属、柽柳属植 物、沙束、沙棘(Hippophae rhamnoides)等, 并且多 数灌木的气孔器下陷, 降低了水分的气孔性散失。 同时, 从结果可以看出气孔密度的高低与表皮其他 附属物也有关系, 表皮毛和蜡质少的植物, 气孔密 度一般相对较高, 如表皮微形态抗逆适应主要类型 的第(5)、(6)类植物中的骆驼刺、杜柳等。表皮附属 物的基本功能是保护叶片免受不利环境的直接损 伤, 从而调节植物的生理功能。

综上所述, 荒漠植物对环境的适应, 从表皮微 形态结构基本特征来看, 以同化枝为主要光合器官 的植物, 同化枝表皮主要的附属物是角质膜蜡质层 以及气孔器, 基本没有表皮线毛, 如梭梭属、沙拐杳 属、麻黄属的植物等。肉质棒状叶片表皮微形态结 构与同化枝一样也不具有线毛结构, 如黑果枸杞、

红砂属植物、霸王、盐爪爪、沙葱等。同化枝和棒 状叶片表皮附属物蜡质层晶体形态各异, 蜡质层厚 度与植物的抗旱性密切相关。不同生活型植物中, 草本的蜡质片层相对较少, 多数灌木都具有较厚的 角质膜蜡质层。表皮附属物线毛结构在多数片状叶 片中基本都可以见到, 线毛的形态结构多样化程度 很高, 基本结构分为有囊和无囊两类, 形态各异。线 毛在表皮的分布密度从零星分布到完全覆盖的都 有, 多数密度较高。对于大多数荒漠植物而言, 线毛 密度低, 则蜡质层晶体密度高, 线毛和蜡质晶体相 互协调覆盖叶片表皮。表皮线毛和蜡质晶体覆盖少 的植物, 则气孔密度相对较高, 气孔密度最高的荒 漠植物叶片见于上表面无气孔器的, 如蒙古扁桃、 杜柳等。灌木的气孔下陷较深, 以降低水分的气孔 性散失, 草本植物的气孔基本不深陷。从荒漠植物 叶片表皮的主要功能来看, 荒漠植物叶表皮微形态 结构的适应特征是表皮附属物(主要是线毛和角质 膜蜡质层)与表皮结构(凹凸、乳突和气孔器等)相互 协调, 共同抵御强光, 降低叶片的蒸腾并吸收空气 中的水汽来适应干旱和其他不利的荒漠环境条件。
基金项目 国家重点基础研究发展计划(973计划) (2013CB429904)和国家自然科学基金(91125029)。

\section{参考文献}

Adebowale A, Naidoo Y, Lamb J, Nicholas A (2014). Comparative foliar epidermal micromorphology of Southern African Strychnos L. (Loganiaceae): Taxonomic, ecological and cytological considerations. Plant Systematics and Evolution, 300, 127-138.

Aliero AA, Grierson DS, Afolayan AJ (2006). The foliar micromorphology of Solanum pseudocapsicum. Flora, 201, 326-330.

Arena C, Vitale L, de Santo VA (2008). Paraheliotropism in Robinia pseudoacacia L.: An efficient strategy to optimise photosynthetic performance under natural environmental conditions. Plant Biology, 10, 194-201.

Aronne G, de Micco V (2001). Seasonal dimorphism in the Mediterranean Cistus incanus L. subsp. incanus. Annal Botany, 87, 789-794.

Bargel H, Barthlott W, Koch K, Schreiber L, Neinhuis C (2004). Plant cuticles: Multifunctional interfaces between plant and environment. In: Hemsley AR, Poole I eds. Evolution of Plant Physiology. Academic Press, London. 171-194.

Barthlott W (1981). Epidermal and seed surface characters of plants: Systematic applicability and some evolutionary aspects. Nordic Journal of Botany, 1, 345-355.

Bosabalidis AM, Kofidis G (2002). Comparative effects of drought stress on leaf anatomy of two olive cultivars. Plant Science, 163, 375-379.

Cameron RJ (1970). Light intensity and the growth of Eucalyptus seedlings II. The effect of cuticular waxes on light absorption in leaves of Eucalyptus species. Australia Journal of Botany, 18, 275-284.

Casson SA, Hetherington AM (2010). Environmental regulation of stomatal development. Current Opinion of Plant Biology, 13, 90-95.

Chaves MM, Maroco JP, Pereira JS (2003). Understanding plant responses to drought-From genes to the whole plant. Functional Plant Biology, 30, 239-264.

Chen G, Sun W, Sun H (2010). Leaf epidermal characteristics of Asiatic buddleja L. under scanning electron microscope: Insights into chromosomal and taxonomic significance. Flora, 205, 777-785.

Chi LH, Song FB (2006). Analyse of leaves' structure character and ecological adaptation of ten plants in the west alkaline district of Songnen plain. Ecology and Environment, 15, 1269-1273. (in Chinese with English abstract) [迟丽华, 宋风斌 (2006). 松嫩平原西部盐碱地区10种植物叶片 结构特征及其生态适应性. 生态环境, 15, 1269-1273.]

de Micco V, Aronne G (2012). Morpho-anatomical traits for plant adaptation to drought. In: Aroca R ed. Plant Responses to Drought Stress. Springer, Berlin.

Deng M, Hipp A, Song Y, Li Q, Coombes A, Cotton A (2014). 
Leaf epidermal features of Quercus subgenus Cyclobalanopsis (Fagaceae) and their systematic significance. Botanical Journal of the Linnean Society, 176, 224-259.

Dickison WC (2000). Integrative Plant Anatomy. Academic Press, San Diego, USA.

Editorial Committee of Flora of China, Chinese Academy of Sciences (1998). Flora of China. Science Press, Beijing. (in Chinese) [中国科学院中国植物志编辑委员会 (1998). 中国植物志. 科学出版社, 北京.]

Ehleringer J, Bjorkman O (1978). Pubescence and leaf spectral characteristics in a desert shrub, Encelia farinosa. Oecologia, 36, 137-148.

Ehleringer J, Bjorkman O, Mooney HA (1976). Leaf pubescence: Effects on absorptance and photosynthesis in a desert shrub. Science, 192, 376-377.

Ehleringer JR, Mooney HA (1978). Leaf hairs: Effects on physiological activity and adaptive value to a desert shrub. Oecologia, 37, 183-200.

Francisco A, Porto M, Ascensao L (2015). Morphological phylogenetic analysis of Ophrys (Orchidaceae): Insights from morpho-anatomical floral traits into the interspecific relationships in an unresolved clade. Botanical Journal of the Linnean Society, 179, 454-476.

Gairola S, Naidoo Y, Bhatt A, Nicholas A (2009). An investigation of the foliar trichomes of Tetradenia riparia (Hochst.) Codd [Lamiaceae]: An important medicinal plant of Southern Africa. Flora, 204, 325-330.

Gan Y, Zhou L, Shen ZJ, Shen ZX, Zhang YQ, Wang GX (2010). Stomatal clustering, a new marker for environmental perception and adaptation in terrestrial plants. Botanical Studies, 51, 325-336.

Gao JP, Wang YH, Chen DF (2003). Anatomical characteristics of leaf epidermis and vessel elements of Schisandra sphenanthera from different districts and their relationships to environmental factors. Acta Botanica Boreali-Occidentalia Sinica, 23, 715-723. (in Chinese with English abstract) [高 建平, 王彦涵, 陈道峰 (2003). 不同产地华中五味子叶 表皮结构和导管分子的解剖学特征及其与环境因子的 关系. 西北植物学报, 23, 715-723.]

Ghahremaninejad F, Khalili Z, Maassoumi AA, MirzaieNodoushan H, Riahi M (2012). Leaf epidermal features of Salix species (Salicaceae) and their systematic significance. American Journal of Botany, 99, 769-777.

Gielwanowska I, Szczuka E, Bednara J, Gorecki R (2005). Anatomical features and ultrastructure of Deschampsia antarctica (Poaceae) leaves from different growing habitats. Annals of Botany, 96, 1109-1119.

Gomes MP, Marques TCLLSM, Nogueira MOG, de Castro EM, Soares AM (2011). Ecophysiological and anatomical changes due to uptake and accumulation of heavy metal in Brachiaria decumbens. Scientific Agriculture, 68, 566-573.

Gregoriou K, Pontikis K, Vemmos S (2007). Effects of reduced irradiance on leaf morphology, photosynthetic capacity, and fruit yield in olive (Olea europaea L.). Photosynthetica, 45, 172-181.

Guo H, Gao Y, Ma C, Ren A, Wu J (2008). Genetic diversity and genetic relationship of Caragana microphylla, Caragana davazamcii and Caragana korshinskii on the Inner Mongolia Plateau, China. Acta Ecologica Sinica, 28, 3729-3736.

He JS, Chen WL, Wang XL (1994). Morphological and anatomical features of Quercus section Suber and its adaptation to the ecological environment. Acta Phytoecologica Sinica, 18, 219-227. (in Chinese with English abstract) [贺 金生, 陈伟烈, 王勋陵 (1994). 高山栎叶的形态结构及 其与生态环境的关系. 植物生态学报, 18, 219-227.]

Hickey LJ (1984). Changes in the angiosperm flora across the cretaceus tertiary boundary. In: Bergren WA, van Couvering JA eds. Catastrophes and Earth History. Princeton University Press, Princeton, USA.

Holmes MG, Keiller DR (2002). Effects of pubescence and waxes on the reflectance of leaves in the ultraviolet and photosynthetic wavebands: A comparison of a range of species. Plant, Cell \& Environment, 25, 85-93.

Jaleel CA, Gopi R, Azooz MM, Panneerselvam R (2009a). Leaf anatomical modifications in Catharanthus roseus as affected by plant growth promoters and retardants. Global Journal of Molecular Science, 4, 1-5.

Jaleel CA, Manivannan P, Wahid A, Farooq M, Jasim Al-Juburi H, Somasundaram R, Panneerselvam R (2009b). Drought stress in plants: A review on morphological characteristics and pigments composition. International Journal of Agriculture and Biology, 11, 100-105.

Karabourniotis G, Papadopoulos K, Papamarkou M, Manetas Y (1992). Ultraviolet-B radiation absorbing capacity of leaf hairs. Physiologia Plantarum, 86, 414-418.

Kenzo T, Yoneda R, Azani MA, Majid NM (2008). Changes in leaf water use after removal of leaf lower surface hairs on Mallotus macrostachyus (Euphorbiaceae) in a tropical secondary forest in Malaysia. Journal of Forest Research, 13, 137-142.

Klich MG (2000). Leaf variations in Elaeagnus angustifolia related to environmental heterogeneity. Environmental and Experimental Botany, 44, 171-183.

Koch K, Bhushan B, Barthlott W (2009). Multifunctional surface structures of plants: An inspiration for biomimetics. Progress of Material Science, 54, 137-178.

Koch K, Ensikat HJ (2008). The hydrophobic coatings of plant surfaces: Epicuticular wax crystals and their morphologies, crystallinity and molecular self-assembly. Micron, 39, 759772.

Kong HZ (2001). Comparative morphology of leaf epidermis in the Chloranthaceae. Botanical Journal of Linnean Society, 136, 279-294.

Kremer D, Dunkic V, Ruscic M, Matevski V, Ballian D, Bogunic 
F, Eleftheriadou E, Stesevic D, Kosalec I, Bezic N, Stabentheiner E (2014). Micromorphological traits and essential oil contents of Micromeria kerneri Murb. and M. juliana (L.) Benth. (Lamiaceae). Phytochemistry, 98, 128-136.

Krober W, Heklau H, Bruelheide H (2015). Leaf morphology of 40 evergreen and deciduous broad leaved subtropical tree species and relationships to functional ecophysiological traits. Plant Biology, 17, 373-383.

Lakusic B, Stevanovic B, Jancic R, Lakusic D (2010). Habitatrelated adaptations in morphology and anatomy of Teucrium (Lamiaceae) species from the Balkan Peninsula (Serbia and Montenegro). Flora, 205, 633-646.

Liu Y, Li X, Chen G, Li M, Liu M, Liu D (2015). Epidermal micromorphology and mesophyll structure of Populus euphratica heteromorphic leaves at different development stages. PLOS ONE, 10, e0137701. doi:10.1371/journal. pone.0137701.

Liu Y, Li X, Liu M, Cao B, Tan H, Wang J, Li X (2012). Responses of three different ecotypes of reed (Phragmites communis Trin.) to their natural habitats: Leaf surface micro-morphology, anatomy, chloroplast ultrastructure and physio-chemical characteristics. Plant Physiology and Biochemistry, 51, 159-167.

Liu YX (1987). Desert Flora of China, Vol. 2. Science Press, Beijing. (in Chinese) [刘瑛心 (1987). 中国沙漠植物志, 第2卷. 科学出版社, 北京.]

Ma CC, Gao YB, Guo HY, Wang JL (2003). Interspecific transition among Caragana microphylla, C. davazamcii and $C$. korshinskii along geographic gradient I. Ecological and RAPD evidence. Acta Botany Sinica, 45, 1218-1227.

Ma J, Li JZ, Chao Z, Zhang HW, Liu CM (2003). A study on microstructural feature of the seeds of desert plants in northwest China. Journal of Zhejiang Normal University (Natural Science Edition), 26, 109-115. (in Chinese with English abstract) [马骥, 李俊祯, 昆志, 张宏伟, 刘传明 (2003). 64种荒漠植物种子微形态的研究. 浙江师范大 学学报(自然科学版), 26, 109-115.]

Ma J, Wang XL, Zhao SL (1997). A study on the seeds micromorphological characteristics of Peganum from China northwest and its taxonomic and ecological significance. Journal of Wuhan Botanical Research, 4, 323-327. (in Chinese with English abstract) [马瀷, 王勋陵, 赵松岭 (1997). 骆驼蓬属种子微形态及其生态学与分类学意义. 武汉植物学研究, 4, 323-327.]

Munien P, Naidoo Y, Naidoo G (2015). Micromorphology, histochemistry and ultrastructure of the foliar trichomes of Withania somnifera (L.) Dunal (Solanaceae). Planta, 242, 1107-1122.

Navarro T, Oualidi JE (1999). Trichome morphology in Teucrium L. (Labiatae). A taxonomic review. Anales del Jardin Botanico de Madrid, 57, 277-297.

Noman A, Hameed M, Ali Q, Aqeel M (2012). Foliar tissue architectural diversity among three species of genus $\mathrm{Hi}$ - biscus for better adaptability under industrial environment. International Journal of Environmental Science, 2, 22122222.

Ogle K, Reynolds JF (2004). Plant responses to precipitation in desert ecosystems: Integrating functional types, pulses, thresholds, and delays. Oecologia, 141, 282-294.

Pal A, Kulshreshtha K, Ahmed KJ, Behl HM (2002). Do leaf surface characters play a role in plant resistance to auto-exhaust pollution? Flora, 197, 47-55.

Perez-Estrada LB, Cano-Santana Z, Oyama K (2000). Variation in leaf trichomes of Wigandia urens: Environmental factors and physiological consequences. Tree Physiology, 20, 629-632.

Perrone R, de Rosa P, de Castro O, Colombo P (2013). Leaf and stem anatomy in eight Hypericum species (Clusiaceae). Acta Botanica Croatica, 72, 269-286.

Perrone R, Salmeri C, Brullo S, Colombo P, de Castro O (2015). What do leaf anatomy and micro-morphology tell us about the psammophilous Pancratium maritimum L. (Amaryllidaceae) in response to sand dune conditions? Flora, 213, 20-31.

Qi RH, Li YZ, Fan JP (1998). The idioblasts and their ecological significance in leaves of 16 alpine plants. Acta Botanica Boreali-Occidentalia Sinica, 18, 270-276. (in Chinese with English abstract) [祁如虎, 李有忠, 范建平 (1998). 16种高山植物叶片内的异细胞及其生态学意义. 西北植物学报, 18, 270-276.]

Retamales HA, Scharaschkin T (2015). Comparative leaf anatomy and micromorphology of the Chilean Myrtaceae: Taxonomic and ecological implications. Flora, 217, 138154.

Roth I (1984). Stratification of Tropical Forests As Seen in Leaf Structure. Dr W Junk Publishers, Hague.

Rusydi A, Talip N, Latip J, Rahman RA, Sharif I (2013). Morphology of trichomes in Pogostemon cablin Benth. (Lamiaceae). Australian Journal of Crop Science, 7, 744-749.

Sam O, Jerez E, Dell'amiico J, Ruiz Sanchez MC (2000). Water stress induced changes in anatomy of tomato leaf epidermis. Biologia Plantarum, 43, 275-277.

Scatena VL, Giulietti AM, Borba EL, van den Berg C (2005). Anatomy of Brazilian Eriocaulaceae: Correlation with taxonomy and habitat using multivariate analyses. Plant Systematics and Evolution, 253, 1-22.

Shafiee-Hajiabad M, Hardt M, Honermeier B (2014). Comparative investigation about the trichome morphology of common oregano (Origanum vulgare L. subsp. vulgare) and Greek oregano (Origanum vulgare L. subsp. hirtum). Journal of Applied Research on Medicinal and Aromatic Plants, 1, 50-58.

Shepherd T, Wynne GD (2006). The effects of stress on plant cuticular waxes. New Phytologist, 171, 469-499.

Shield LM (1950). Leaf xeromorphy as related to physiological and structural influences. Botanical Review, 16, 4399-

www.plant-ecology.com 
4471.

Smith WK, Nobel PS (1977). Influences of seasonal changes in leaf morphology on water-use efficiency for three desert broadleaf shrubs. Ecology, 58, 1033-1043.

Stenglein SA, Arambarri AM, Balatti PA (2005). Leaf epidermal characters related with plant's passive resistance to pathogens vary among accessions of wild beans Phaseolus vulgaris var. aborigineus (Leguminosae-Phaseoleae). Flora, 200, 285-295.

Talukdar T (2015). Micromorphomics: A morphological dissection to unveil environmental stress. In: Barh D, Khan MS, Davies E eds. Plant Omics: The Omics of Plant Science. Springer, New Delhi, India. 615-632.

Tissier A (2012). Trichome specific expression: Promoters and their applications. In: Ciftci YO ed. Transgenic PlantsAdvances and Limitations. Tech Europe, Rijeka, Croatia.

Turner IM (2001). The Ecology of Trees in the Tropical Rain Forest. Cambridge University Press, Cambridge, UK.

Wagner P, Furstner R, Barthlott W, Neinhuis C (2003). Quantitative assessment to the structural basis of water repellency in natural and technical surfaces. Journal of Experimental Botany, 54, 1295-1303.

Wang DC, Yang YP, Chen JH, Li X (2012). Leaf epidermal microfeatures of 28 Salix species under scanning electronic microscope and their taxonomical significances. Plant Diversity and Resources, 34, 430-442. (in Chinese with English abstract) [王东超, 杨永平, 陈家辉, 李馨 (2012). 28种柳属植物的叶表皮微形态特征及其分类学 意义. 植物分类与资源学报, 34, 430-442.]

Wang XL (1993). Advances of plant ecological anatomy. Chinese Bulletin of Botany, 10(Suppl.), 1-10. (in Chinese with English abstract) [王勋陵 (1993). 植物生态解剖学研究 发展. 植物学通报, 10(Suppl.), 1-10.]

Wang XL, Ma J (1999). A study on leaf-structure and the diversity of xerophytes ecology adaptation. Acta Ecologica Sinica, 19, 787-792. (in Chinese with English abstract) [王 勋陵, 马骥 (1999). 从旱生植物叶结构探讨其生态适应 的多样性. 生态学报, 19, 787-792.]

Wang XL, Wang J (1989). Plant Morphology, Structure and Environment. Lanzhou University Press, Lanzhou. (in Chinese) [王勋陵, 王静 (1989). 植物形态结构与环 境. 兰州大学出版社, 兰州.]

Werker E (1993). Function of essential oil-secreting glandular trichome in aromatic plants of the Lamiaceae-A review. The Flavour and Fragrance Journal, 8, 249-255.

Wuenscher JE (1970). The effect of leaf hairs of Verbascum thapsus on leaf energy exchange. New Phytologist, 69, 65-73.
Xu Z, Zhou G (2008). Responses of leaf stomatal density to water status and its relationship with photosynthesis in a grass. Journal of Experimental Botany, 59, 3317-3325.

Yan QD, Su PX, Chen HB, Zhang LM (2008). Comparative studies on crystal idioblasts of five $\mathrm{C}_{4}$ desert plants. Journal of Plant Ecology (Chinese Version), 32, 873-888. (in Chinese with English abstract) [严巧娣, 苏培胥, 陈宏涁, 张岭梅 (2008). 五种 $\mathrm{C}_{4}$ 荒漠植物光合器官中含晶细胞 的比较分析. 植物生态学报, 32, 873-888.]

Yang MB, Yang JL, Yang JY, Liang N, Qing H (2007). Changes on characteristics of the leaf epidermis and genetic diversity of Caragana davazamcii in different habitats in Ordos plateau, China. Journal of Plant Ecology (Chinese Version), 31, 1181-1189. (in Chinese with English abstract) [杨明博, 杨吉力, 杨九艳, 梁娜, 清华 (2007). 鄂尔多斯 高原不同生境条件下中间锦鸡儿植物叶片表皮特征及遗 传多样性变化分析. 植物生态学报, 31, 1181-1189.]

Zhang Y, Zeng C, Li D (2014). Scanning electron microscopy of the leaf epidermis in Arundinarieae (Poaceae: Bambusoideae): Evolutionary implications of selected micromorphological features. Botanical Journal of the Linnean Society, 176, 46-65.

Zhao HL (2012). Desert Ecology. Science Press, Beijing. (in Chinese) [赵哈林 (2012). 沙漠生态学. 科学出版社, 北京.]

Zhao XX, Li Y, Su SP, Bai X (2014). Drought resistance analysis based on anatomical structures of assimilating shoots of Calligonum mongolicum from three geographic populations. Journal of Desert Research, 34, 1293-1300. (in Chinese with English abstract) [赵小仙, 李毅, 苏世 平, 白潇 (2014). 3个地理种群蒙古沙拐杳同化枝解剖 结构及抗旱性比较. 中国沙漠, 34, 1293-1300.]

Zhou W, Xia NH (2012). Leaf epidermal features of Lithocarpus (Fagaceae) from China and their systematic significance. Botanical Journal of Linnean Society, 168, 216-228.

Zhou ZB, Li PJ (2002). A review on the phytotomy research of xerophytes in China. Arid Zone Research, 19(1), 35-40. (in Chinese with English abstract) [周智斌, 李培军 (2002). 我国旱生植物的形态解剖学研究. 干旱区研究, 19(1), 35-40.]

Zhu GL, Deng RH, Wei XZ (2016). Leaf epidermal micromorphology of Ziziphus jujuba var. spinosa in response to a gradient of drought stress. Acta Ecologica Sinica, 36, 1-11. (in Chinese with English abstract) [朱广龙, 邓荣华, 魏学智 (2016). 酸柊叶表皮微形态对不同生态环境的 适应特征. 生态学报, 36, 1-11.]

责任编委: 何维明 责任编辑: 王 葳

附录I 荒漠植物叶片采集的物种种类、采集地理位置、植物生活型及采集时间

Appendix I List of the species, collection sites, life form and selected time of desert plants in this study http://www.plant-ecology.com/fileup/PDF/cjpe.2016.0129-A1.PDF 


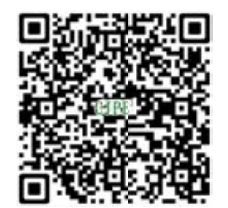

植物生态学报官网

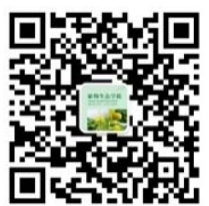

微信订阅号

期刊及学科

相关信息发布

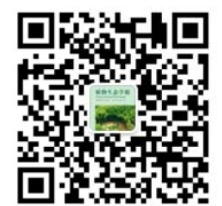

微信服务号

稿件状态查询

全文检索汶览 